\title{
Double membrane based on lidocaine-coated polymyxin-alginate nanoparticles for wound healing: In vitro characterization and in vivo tissue repair
}

\author{
D.M.L. Oliveira ${ }^{\mathrm{a}, \mathrm{b}}$, P.S. Rezende ${ }^{\mathrm{a}}$, T.C. Barbosa ${ }^{\mathrm{a}}$, L.N. Andrade ${ }^{\mathrm{a}, \mathrm{b}}$, C. Bani ${ }^{\mathrm{c}}$, D.S. Tavares ${ }^{\mathrm{c}}$, C. \\ F. da Silva ${ }^{\mathrm{d}}$, M.V. Chaud ${ }^{\mathrm{e}}$, F. Padilha ${ }^{\mathrm{a}, \mathrm{b}}$, A. Cano ${ }^{\mathrm{f}, \mathrm{g}, \mathrm{h}}$, R.L.C. de Albuquerque Júnior ${ }^{\mathrm{a}, \mathrm{b}}$, E. \\ B. Souto ${ }^{\text {h, i, },}$, P. Severino ${ }^{a, b, j, *}$
}

${ }^{a}$ University of Tiradentes (Unit), Biotechnological Postgraduate Program, Av Murilo Dantas, 300, 49010-390 Aracaju, Brazil

${ }^{\mathrm{b}}$ Institute of Technology and Research (ITP), Nanomedicine and Nanotechnology Laboratory (LNMed), Av Murilo Dantas, 300, 49010-390 Aracaju, Brazil

${ }^{\mathrm{c}}$ Department of Morphology, Federal University of Sergipe (UFS), Avenida Marechal Rondon, 49100-000 São Cristovão, Brazil

${ }^{\mathrm{d}}$ Department of Exact and Earth Sciences, Federal University of São Paulo, Rua Arthur Riedel, 275, Diadema 09972-270, Brazil

${ }^{\mathrm{e}}$ Laboratory of Biomaterials and Nanotechnology for the Development and Evaluation of Bioactive Substances, University of Sorocaba, Rodovia Raposo Tavares Km 925, 18023-000 Sorocaba, São Paulo, Brazil

${ }_{\mathrm{f}}^{\mathrm{f}}$ Institute of Nanoscience and Nanotechnology (IN2UB), University of Barcelona, Barcelona, Spain

${ }^{g}$ Biomedical Research Networking Centre in Neurodegenerative Diseases (CIBERNED), Madrid, Spain

${ }^{\mathrm{h}}$ Department of Pharmaceutical Technology, Faculty of Pharmacy, University of Coimbra, Pólo das Ciências da Saúde, Azinhaga de Santa Comba, $3000-548$ Coimbra, Portugal

${ }^{\mathrm{i}}$ CEB - Centre of Biological Engineering, University of Minho, Campus de Gualtar, 4710-057 Braga, Portugal

${ }^{\mathrm{j}}$ Tiradentes Institute, 150 Mt Vernon St, Dorchester, MA 02125, USA

\section{A R T I C L E I N F O}

\section{Keywords:}

Double membrane

Polymyxin B sulphate

Lidocaine hydrochloride

Solid lipid nanoparticles

Burst release

Controlled release

\begin{abstract}
A B S T R A C T
The aim of this study was to develop and characterize a double layer biomembrane for dual drug delivery to be used for the treatment of wounds. The membrane was composed of chitosan, hydroxypropyl methylcellulose and lidocaine chloride (anesthetic drug) in the first layer, and of sodium alginate-polymyxin B sulphate (antibiotic) nanoparticles as the second layer. A product with excellent thickness $(0.01-0.02 \mathrm{~mm})$, adequate mechanical properties with respect to elasticity, stiffness, tension, and compatible $\mathrm{pH}$ for lesion application has been successfully obtained. The incorporation of the drugs was confirmed analysing the membrane cross-sections by scanning electron microscopy. A strong interaction between the drugs and the functional groups of respective polymers was confirmed by Fourier-Transform Infrared Spectroscopy, thermal analysis and X-ray diffraction. Microbiological assays showed a high antimicrobial activity when polymyxin B was present to act against the Staphylococcus aureus and Pseudomonas aeruginosa strains. Low cytotoxicity observed in a cell viability colorimetric assay and SEM analysis suggest biocompatibility between the developed biomembrane and the cell culture. The in vivo assay allowed visualizing the healing potential by calculating the wound retraction index and by histological analysis. Our results confirm the effectiveness of the developed innovative biomaterial for tissue repair and regeneration in an animal model.
\end{abstract}

Abbreviations: ALG, sodium alginate; CS, chitosan; DS, degree of swelling; DSC, Differential Scanning Calorimetry; FTIR, Fourier-Transform Infrared Spectroscopy;

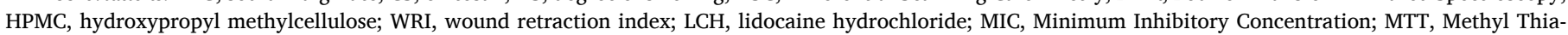
zolyl Tetrazolium; PBS, phosphate-buffered saline; PLX, polimixin; SEM, scanning electron microscopy; XRD, X-ray diffraction.

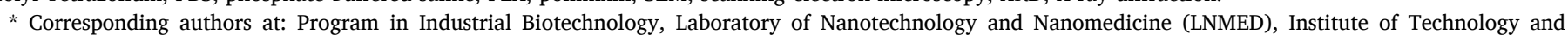

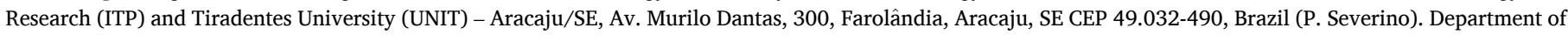

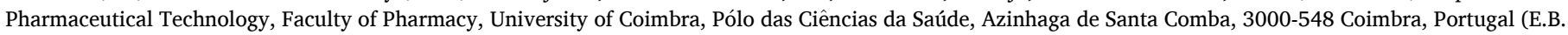
Souto).

E-mail addresses: ebsouto@ff.uc.pt (E.B. Souto), patricia_severino@itp.org.br (P. Severino). 


\section{Introduction}

The treatment of skin lesions is a challenging task due to its high cost, prolonged hospitalization of the patients, and partial or permanent loss of working capacity. The latest Global Burden Disease study estimated that skin disorders are the 4th leading cause of non-fatal disease burden worldwide (Karimkhani et al., 2017; Seth et al., 2017). Ideal treatment approaches should include the stimulation of wound granulation, decrease of oedema, fluid and debris, and also the reduction of local bacterial contamination and pain (Andersen, 2019). The loss of skin integrity results in an imbalance of tissue homeostasis, as the complex, multifactorial, and continuous tissue repair process involves specific cellular mechanism and extracellular elements, such as cytokines and growth factors (Milcheski et al., 2017).

The use of biomaterials for wound healing has received increasing interest over the last years (Barbosa et al., 2016; Diniz et al., 2020; Hissae Yassue-Cordeiro et al., 2019). Biomaterials have been widely used in the fabrication of several controlled drug delivery systems (Gupta et al., 2017; Ramasamy et al., 2020; Ramasamy et al., 2017). For skin administration, the drug delivery system should be adhesive to maximize the contact with the epidermis and offer a prolonged release of the drug over an estimated time-period at the lesion area (FonsecaSantos and Chorilli, 2017; Souto et al., 2017). Natural biopolymers (e.g. chitosan, collagen, hyaluronic acid, and gelatine), have been widely employed either alone or in combination, with proven advantages in optimizing the wound healing process (Chantre et al., 2019; Severino et al., 2018).

The qualitative and quantitative selection of the excipients is instrumental in formulation development since these latter influence the spatial and temporal release of the drug from the delivery system significantly, and thus its therapeutic performance. It should be therefore carefully considered the physicochemical characteristics that influence adherence, mucosal irritation, and uncomfortable feeling (Morales et al., 2017; Teo et al., 2017). Membrane devices are a promising alternative for wound healing; the muco-adhesiveness is a strategy to increase the residence time of drugs in the body, improving its bioavailability and therapeutic efficacy. Also, membranes can promote the gradual release of drugs at specific target sites, thus reducing the systemic drug toxicity (Desai, 2018).

Among natural polymers, alginate is considered a hemocompatible biomaterial, easily metabolised and does not undergo accumulation in any organ or tissue. Likewise, its solubility in aqueous medium makes this polymer an interesting alternative for biomedical applications. Alginate is obtained from the extraction of algae and it is characterized as being an anionic polymer derived from the sodium salt of alginic acid. Due to its inert, biocompatible, biodegradable character, alginate is being widely used in healing processes, being able to form membranes with excellent mucoadhesive properties. In the literature, several uses of alginate for skin healing have been described (Diniz et al., 2020; Shtenberg et al., 2018). The mechanically resistance promoted by the combination of two oppositely charged polyelectrolytes is commonly used in the fabrication of particles, sponges, and membranes.

Polymyxins are polypeptide antibiotics with intense action on gramnegative bacteria, which is desired in wound infections (Harm et al., 2016). Also, the presence of an anesthetic drug in the developed membrane for burst release promotes pain relief. Lidocaine is an amide-type local anesthetic and antiarrhythmic class Ib; due to its biopharmaceutical properties, this drug has been successfully used in a variety of formulations for topical anesthesia. Lidocaine shows limited systemic absorption and the induced analgesic effect results from the blocking sodium channels in afferent nerves (Smith et al., 2018).

Production of nanoparticles by the formation of a polyelectrolyte complex in which electrostatic interaction occurs between the amino groups of polymyxins and the carboxyl groups of the alginate, offers the possibility to achieve a controlled release of loaded drugs (Severino et al., 2015; Severino et al., 2017). We have previously seen that this binding keeps the antimicrobial action of polymyxins and controlled release.

Chitosan is also widely employment as biomaterial for skin healing (Debone et al., 2019). Chitosan is derived from exoskeleton of crustaceans, it shows hemostatic, fungicidal, antibacterial properties, and the ability to stimulate cell migration and proliferation by reorganizing the cell histoarchitecture. One of its most common uses is in the formation of biomembranes (Barbosa et al., 2016; Behera et al., 2017). Some of the drugs already loaded into alginate and/or chitosan membranes reported in the literature are ibuprofen (Morgado et al., 2017), norfloxacin (Mahmoud and Salama, 2016), prazosin (Kulkarni et al., 2010), nifedipine (Thacharodi and Rao, 1996), among others.

The aim of this work has been the development and characterisation of a double-layer membrane for the dual delivery of the antibiotic polymyxin and the local anesthetic lidocaine. A blend of chitosan and hydroxypropyl methyl cellulose polymers containing lidocaine has been used as the first layer. This layer was then coated with a second layer composed of alginate-polymyxin nanoparticles, aiming to achieve a burst release of the anesthetic followed by a sustained release of the antibiotic drug.

\section{Materials and methods}

\subsection{Materials}

Polymyxin B sulphate (PLX) and lidocaine hydrochloride (LCH) were kindly provided by Cristalia (Itapira, São Paulo, Brazil). Sodium alginate (ALG, $150-170$ Da/Protanal ${ }^{\circledR}$ 6650) was received from FMC Biopolymer (Philadelphia, PA, USA). Chitosan (CS), with a degree of acetylation (DA) of $82.83 \pm 3.63$ and a molar mass of $296.6 \mathrm{kDa}$ was obtained from Polymer (São Paulo, SP, Brazil). Hydroxypropyl methyl cellulose (HPMC, Methocel ${ }^{\mathrm{TM}} \mathrm{K} 100 \mathrm{CR}, 80,000-120,000 \mathrm{cP}$ apparent viscosity $2 \%$ in water at $20{ }^{\circ} \mathrm{C}$ ) and sorbitol were bought from Henrifarma (São Paulo, SP, Brazil). Double distilled water was used after filtration in a Millipore ${ }^{\circledR}$ system (home supplied). All other reagents were purchased by Sigma-Aldrich (Sintra, Portugal).

\subsection{Preparation of the dual membranes}

The membranes were produced by the casting method. The first layer was composed of CS, HPMC, sorbitol, LCH, and PLX, which were solubilized in an aqueous acetic acid solution $(5 \% \mathrm{w} / \mathrm{v})$. Then, the obtained product was poured into Petri dishes and kept in an oven (TECNAL TE$393 / 2$, Piracicaba, SP, Brazil) at $40{ }^{\circ} \mathrm{C}$ for $30 \mathrm{~min}$. The production of the PLX-loaded solid lipid nanoparticles (PLX-SLN) (to form the second layer) has been previously described by us (Severino et al., 2015). Briefly, the aqueous surfactant solution, composed of polysorbate 20 $(0.45 \mathrm{w} / \mathrm{v})$, trioleate sorbitan $(0.045 \mathrm{w} / \mathrm{v})$ and heated at $80{ }^{\circ} \mathrm{C}$, was slowly added to the melted lipid phase (cetyl alcohol $1 \% \mathrm{w} / \mathrm{v}$ ) containing PLX. A hot emulsion was obtained by higher shear homogenization using the Ultra-Turrax ${ }^{\circledR}$ (IKA, model T25, impeller $10 \mathrm{G}$, Königswinter, Germany) for $3 \mathrm{~min}$ and applying 10,000 rpm. The hot o/ $\mathrm{w}$ emulsion was then passed in a high-pressure homogenizer (GEA Niro Soavi, model NS1001L2K, Panda $2 \mathrm{~K}$, Parma, Italy) at $80{ }^{\circ} \mathrm{C}$ applying 500 bar pressure and 5 homogenization cycles. Freshly prepared PLXSLN were poured onto the previous layer, maintaining them in an oven at $40{ }^{\circ} \mathrm{C}$ for $24 \mathrm{~h}$. Table 1 shows the selected concentrations of each component used in the formulation.

\subsection{Scanning electron microscopy}

The morphology of the membranes was analysed by scanning electron microscopy (SEM). The membranes were cut in $2 \times 1 \mathrm{~cm}^{2}$ sections and maintained in an environment with silica gel activated for $24 \mathrm{~h}$. These were then cryofuffed with liquid nitrogen, fixed in suitable metallic support (mini Sputter coater, SC 7620) by depositing a thin 
Table 1

The composition of membranes formulations.

\begin{tabular}{|c|c|c|c|c|c|c|c|}
\hline \multirow[t]{2}{*}{ Membranes } & \multicolumn{5}{|l|}{ Layer 1} & \multicolumn{2}{|l|}{ Layer 2} \\
\hline & Chitosan & HPMC & Sorbitol & Lidocaine Hydrochloride & Polymyxin sulfate & Sodium alginate & Polymyxin sulfate \\
\hline $\mathrm{F} 1$ & & & & & & 2 & \\
\hline F2 & 1 & & & & & & \\
\hline F3 & 1 & 1 & & & & 2 & \\
\hline $\mathrm{F} 4$ & 1 & 1 & 1 & 0.05 & 0.185 & 2 & 0.240 \\
\hline
\end{tabular}

*Percentage values.

layer of gold (thickness of $92 \AA$ ) on their surfaces and images were taken with a Hitachi TM 3000 micoscope (Tokyo, Japan) (Debone et al., 2019).

\subsection{Fourier-Transform Infrared Spectroscopy}

The analyses were performed on an average of 32 scans, in the range of $4000-500 \mathrm{~cm}^{-1}$. The equipment used was a Fourier Transform Infrared Spectrometer (FTIR - Nicolet IS10 - Thermo Scientific, Waltham, MA, USA) (Yassue-Cordeiro et al., 2018).

\subsection{Thermal analysis}

Thermograms curves were determined using a thermoanalytical balance (DTG-60H, Shimadzu, Tokyo, Japan). Membranes were carefully weighed $(\sim 1.50 \mathrm{mg})$ in a platinum pan and heated to temperatures ranging from 25 to $500{ }^{\circ} \mathrm{C}\left(10{ }^{\circ} \mathrm{C} / \mathrm{min}\right)$ under a dynamic nitrogen atmosphere $(100 \mathrm{~mL} / \mathrm{min})$. Differential Scanning Calorimetry (DSC) analyses were performed using a DSC-60 thermal analysis system (Shimadzu, Tokyo, Japan). Approximately $10 \mathrm{mg}$ of samples were weighed into an aluminum pan, sealed, and heated ranging from 25 to $320{ }^{\circ} \mathrm{C}$ under a heating rate of $5^{\circ} \mathrm{C} \mathrm{min}^{-1}$ in a nitrogen inert atmosphere (45 mL/min) (Debone et al., 2019).

\subsection{Mucoadhesion}

Mucoadhesion properties were evaluated using a texture analyzer (TA.XT plus, Stable Micro Systems, Godalming, UK) with $50 \mathrm{~N}$ load cell, according to the procedure described by (Fransén et al., 2008). The cylindrical ended probe (10 mm diameter) was moved downward with a speed of $2.0 \mathrm{~mm} / \mathrm{s}$ until contact with the sample; contact was maintained for 30,60, and $180 \mathrm{~s}$. Afterward, the probe was raised at $2.0 \mathrm{~mm} /$ s. The maximum force required to detach the probe from the sample could be detected directly using Texture Exponent Lite software. The total amount of force involved in probe withdrawal (Wad $-\mu \mathrm{J})$ was determined by calculating the area under the force versus distance curve. The tests were repeated six times in a compression test mode with $2 \mathrm{mN}$ of triggered force (Severino et al., 2018).

\subsection{Mechanical properties of membranes}

The elongation at break, tensile strength, and Young's modulus was measured using a texture analyzer (TA.XT2, Godalming, UK) equipped with a $5 \mathrm{~kg}$ load cell. Membranes were cut into $8 \mathrm{~cm}^{2}(2 \times 4 \mathrm{~cm}) \mathrm{sec}-$ tions. Specimens were tested for breaking at a crosshead speed of 2 $\mathrm{mm} \cdot \mathrm{s}^{-1}$ and a displacement of $10 \mathrm{~mm}$. Analyses were performed in triplicate.

\subsection{Degree of swelling}

The membranes were swelled in phosphate-buffered saline (PBS). Membranes of $2 \mathrm{~cm}$ diameter were weighed and immersed in $30 \mathrm{~mL}$ PBS (pH 6.8) at $37^{\circ} \mathrm{C}$, removed at time intervals of $2 \mathrm{~h}(0,2,4$ and $6 \mathrm{~h})$ and then weighed again. Swelling (\%) was determined, according to Eq. (1).
$D S=\frac{m_{i}-m_{f}}{m_{i}} \times 100$

where DS stands for the degree of swelling (\%), $\mathrm{m}_{\mathrm{i}}$ for the initial sample mass $(\mathrm{g})$, and $\mathrm{m}_{\mathrm{f}}$ for the wet mass at different sample times $(\mathrm{g})$. Results were expressed as the average of three measurements.

\subsection{Cell viability - MTT assay}

The cell viability assay was performed using L929 mouse fibroblasts cell line. The methodology was based on the ISO 10993-5 (2009) (ISO, 2009). L929 cells were seeded into 96 -well plates $\left(0.1 \times 10^{6}\right.$ cells/well) and cultured in Dulbecco's Modified Eagle Medium (DMEM). Cell viability was assessed via the colorimetric method using Methyl Thiazolyl Tetrazolium (MTT). Absorbance was measured at a wavelength of $570 \mathrm{~nm}$ using an automated plate reader (DTX880 Multimode Detector, Beckan Coulter Inc., Packard, ON, Canada). Tests were performed in quadruplicate and then normalized according to Eq. (2).

$\%$ Cell viability $=\frac{\mathrm{Abs}(\text { treated cells })-\mathrm{Abs}(\text { blank })}{\mathrm{Abs}(\text { positive control })-\mathrm{Abs}(\text { blank })} \times 100$

where Abs (treated cells) is the absorbance in the presence of the tested membrane, Abs (positive control) is the absorbance of the cells without treatment, and Abs (negative control) is the absorbance with the membrane drug.

\subsection{Cell adhesion and proliferation by SEM}

L929 fibroblasts were inoculated at a density of $1 \times 10^{5}$ cells/sample and incubated in DMEM culture medium supplemented with $10 \%$ fetal bovine serum, $1 \% \mathrm{~L}$-glutamine and $1 \%$ penicillin-streptomycin and incubated at $37{ }^{\circ} \mathrm{C}$ in an atmosphere containing $5 \% \mathrm{CO}_{2}$ for $24 \mathrm{~h}$. The membranes were sterilized by UV light for 30 min each face, as it was a membrane. Samples were rinsed with PBS and fixed in Karnovsky solution (4\% formaldehyde, $2.5 \%$ glutaraldehyde in PBS) for $24 \mathrm{~h}$. The cells were rinsed in PBS and dehydrated with successive and growing baths of alcoholic solutions. Then, it was immersed in a 50:50 (v: v) ethanol/hexamethyldisilane (HMDS) solution for $30 \mathrm{~min}$ follow up a $100 \%$ HMDS immersion during $30 \mathrm{~min}$, and finally removed and dried under exhaustion for $24 \mathrm{~h}$. The samples were metalized with gold and examined by SEM (SEM, Jeol carry scope JCM-5700, Tokyo, Japan).

\subsection{Minimum inhibitory concentration and inhibition halo}

The minimum inhibitory concentration (MIC) determined the antimicrobial activity of the membrane to get therapeutic levels with lethal or inhibitory capacity for the growth of strains of Staphylococcus aureus (ATCC 25923) and Pseudomonas aeruginosa (ATCC 27853). Colonies were harvested and resuspended to $1.5 \times 108 \mathrm{UFC} \cdot \mathrm{mL}^{-1}$ (turbidity equivalent to $0.5 \mathrm{McF}$ arland standard scale). The bacterial solution was diluted to $1 \times 105$ UFC. $\mathrm{mL}^{-1}$ in Mueller Hinton Broth. Samples were diluted in DMSO at concentrations of $1 \%, 2 \%, 3 \%, 4 \%, 5 \%, 6 \%, 7 \%, 8 \%$ in a volume of $50 \mu \mathrm{L}$ medium, were diluted at concentrations since 1.0 until $0.0019531 \mathrm{mg} \cdot \mathrm{mL}^{-1}$. The negative control was $0.1 \mathrm{~mL}$ of Mueller 
Hinton Broth, and the positive control was $0.05 \mathrm{~mL}$ Mueller Hinton Broth and $0.05 \mathrm{~mL}$ bacterial solution at $1 \times 105 \mathrm{UFC} \cdot \mathrm{mL}^{-1}$ dilution. Plates were incubated at $37{ }^{\circ} \mathrm{C}$ for $20 \mathrm{~h}$. The bacterial suspension (Staphylococcus aureus ATCC 25923 and Pseudomonas aeruginosa ATCC 27853) was prepared for inoculum. The cell culture was performed in phosphate buffer $\mathrm{pH}$ 6.0. The concentration and turbidity of the inoculum were standardized, comparing this with the 0.5 standards of the McFarland scale. $15 \mathrm{~mL}$ of the Muller-Hinton agar was poured into 100 $\mathrm{mm}$ plates and homogenized. After solidification was introduced a swab with a bacterial suspension. The seeded plates were allowed to dry for 5 min at room temperature until agar absorbed and applying to the disccut membranes

\subsection{Healing activity in vivo}

This study was approved by the Ethics Committee on Animal Research of the Tiradentes University (CEUA/UNIT) through Opinion No. 011216, the study was conducted within the ethical and legal standards, in support of Law No. 11794 of 08.10.2008, which establishes procedures for their scientific use, Environmental Crimes Law No. 9.605 of February 12, 1998 and the Ethical Principles for the Use of Laboratory Animals of the Brazilian Society of Laboratory Animal Science (SBCAL/ COBEA). The experiments were performed with $\approx 60$ days old male Wistar rats (Rattus norvegicus) $(200 \pm 50 \mathrm{~g})$. The animals were kept in plastic cages, lined with shavings under controlled conditions $(12 \mathrm{~h}$ light-dark cycle at $25 \pm 2{ }^{\circ} \mathrm{C}$ and $60 \%$ air humidity), receiving commercial feed and water ad libitum. The wounds were performed under general anesthesia with an intraperitoneal injection of $0.1 \mathrm{~mL} / 100 \mathrm{~g}$ weight of a solution consisting of $1 \mathrm{~mL}$ of ketamine $(50 \mathrm{mg})$ and $1 \mathrm{~mL}$ of xylazine $(20 \mathrm{mg})$. The procedure was done with a punch, stainless steel, measuring $8.0 \mathrm{~mm}$ in diameter, maintained without suture (open) and hemostasis. The dorsal region of the animal was standardized for the incision taking as reference the spine along the axis of the animal's body, which was trichotomized and performed antisepsis with $1 \%$ topical povidone-iodine. This incision involves the entire thickness of the integument until visualization of the musculature, to keep the fascia intact. In the immediate postoperative period, the animals received 10 $\mathrm{mg} / \mathrm{kg}$ ketoprofen intramuscularly for three days as a prophylactic dose of postoperative symptomatology.

All animals were identified by groups and each group according to the number of days to analyze the healing process (3rd, 7th, 14th, and 21st day) until euthanasia. Each experimental group and its subgroups were named according to the type of coverage used in the surgical incision as for the control group $\left(\mathrm{G}_{\mathrm{C}}\right)$ wrinkle without treatment, membrane without drug $\left(\mathrm{G}_{\mathrm{F} 3}\right)$ and group of membrane-covered wounds with drugs $\left(\mathrm{G}_{\mathrm{F} 4}\right)$. In the postoperative period, the lesions were controlled with photographic images (Sony-branded camera, 10.1 megapixels) and measured with a digital caliper at the inner edges of the diameter at 0 , 3rd, 7th, 14th, and 21st days. Each animal was euthanized in a carbon dioxide chamber (model CGSCO2G - Beiramar), where they received airflow containing $100 \% \mathrm{CO}_{2}$ for $5 \mathrm{~min}$. After the death of the animals, the similar specimens were removed from the healing area with $3.0 \mathrm{~mm}$ margins and the biological residues were left in the vivarium for the final external destination (Corrêa et al., 2017).

Removal of the specimens was equivalent to a healing area with a $0.5 \mathrm{~cm}$ margin of intact skin around the lesion, deep to the first muscle layer. The removed specimens were fixed in EVA and placed in a plastic container with $10 \%$ buffered formalin solution and $\mathrm{pH} 7.4$ for fixation. They were later hemisected, dehydrated in increasing ethanol solutions at 70, 95 and $100 \%$, diaphanized in xylol and embedded in paraffin (conventional histological technique). Histological sections were obtained from paraffin-embedded samples and subsequently subjected to Haematoxylin/Eosin (HE) and Picrosirius staining (Barreto et al., 2016).

\subsection{Capture and assessment of wound area}

The images were obtained by a camera (Sony 10.1), suspended by a tripod with a distance of $30 \mathrm{~cm}$ from the evaluated area, designed to standardize the capture of the images of the lesions. Wounds were measured on days 0 (immediately after surgery), 3, 7, 14 and 21 days postoperatively (after euthanasia) with the aid of a digital caliper. From the measurements of the wound edges, standardized on the right lateral face and lower side, obtaining the value of their area, the wound contraction was evaluated by the following Eq. (3):

Wound contraction $=[$ initial area - day area of measurement $] \times 100$

\subsection{Statistical analysis}

Two-way analysis of variance (ANOVA) followed by Tukey post hoc test and T-test were employed for statistical analysis. $\mathrm{P} \leq 0.05$ was considered indicative of a statistically significant difference. The study was conducted using the software Microcal Origin v. 7.0 (Origin Lab Corp, Northampton, MA, USA).

\section{Results and discussion}

Images of the surface and the cross-section of the obtained membranes are shown in Fig. 1. Fig. 1(a) and (b) refers to the double layer membrane without drug (F3). The thickness of the layers is directly related to the high viscosity of the chitosan (CS) solution (Wang and Chen, 2014). Fig. 1(c) and (d) refers to the double layer membrane with the drug (F4). The uniformly distribution of nanoparticles on the surface of the membrane is clearly visible, suggesting that the interconnection between ALG and PLX has occurred by ionotropic gelation between the amino $\left(\mathrm{NH}_{3}\right)$ of $\mathrm{PLX}$ and the carboxylic group $\left(\mathrm{COO}^{-}\right)$of the alginate (Severino et al., 2017).

FTIR spectrum has been used to identify functional groups through the specific binding vibration energy detection signal in each type of chemical group. It is widely used to identify unknown substances and interactions between substances to form new composite materials. The FTIR spectra of the polymers (ALG and CS) and drugs (PLX and LCH) were compared with a double layer membrane (F4) and results are shown in Fig. 2.

The main peaks of ALG were $3418 \mathrm{~cm}^{-1}$, attributed to the stretching $\mathrm{O}-\mathrm{H}$ and $1613 \mathrm{~cm}^{-1}$, a corresponding carboxylate group (Wu et al., 2018). The main band of PLX was between 1500 and $1550 \mathrm{~cm}^{-1}$ corresponding to the amine group. The cross-linking of PLX with ALG occurs by the reduction of its hydrophilicity through the interaction of opposite charges of the polymer in question (anion) with the drug (cation). The bonding between ALG and PLX occurred between the carboxyl group (COO-) of the polymer with the amino $\left(\mathrm{NH}_{3}^{+}\right.$) of PLX (between 1500 and $1550 \mathrm{~cm}^{-1}$ ). PLX and polymer interaction suggests a positive outcome, since free PLX shows high toxicity attributed to its amphiphilic and cationic nature (Severino et al., 2015). Therefore, the current strategy to minimize the PLX toxicity is to reduce the number of cationic residues and its amphiphilic character (Insua et al., 2017).

The main peak of CS was at $3417 \mathrm{~cm}^{-1}$, attributed to $\mathrm{O}-\mathrm{H}$ axial and the characteristic band at $1650 \mathrm{~cm}^{-1}$ was assigned to the $-\mathrm{C}=\mathrm{O}$ group of the CS (Wu et al., 2018). Double membrane with drugs (F4) shows spectra of each polysaccharide alone and, as previously noted, they are superimposed on the membrane $\mathrm{F} 4$, which also presented the characteristic peaks of the drugs, especially that of lidocaine $\left(3300 \mathrm{~cm}^{-1}\right.$ and $1550 \mathrm{~cm}^{-1}$ for amine groups, both of medium intensity), considering that this drug does not cross-link because it is only incorporated in the membranes. The bands observed were: (i) the axial stretch band of $\mathrm{OH}$, attributed to the hydroxyl group present in CS between 3440 and 3480 $\mathrm{cm}^{-1}$; and (ii) the 1583 to $1594 \mathrm{~cm}^{-1}$, related to the amides observed in the region of $1500 \mathrm{~cm}^{-1}$ shown in the spectra of the membrane (F4), CS and PLX, which is a cationic drug. The main bands observed in the 


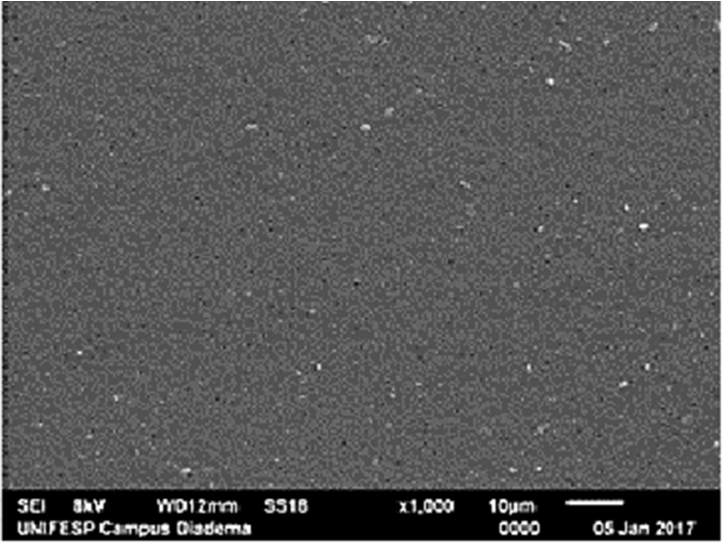

(a)

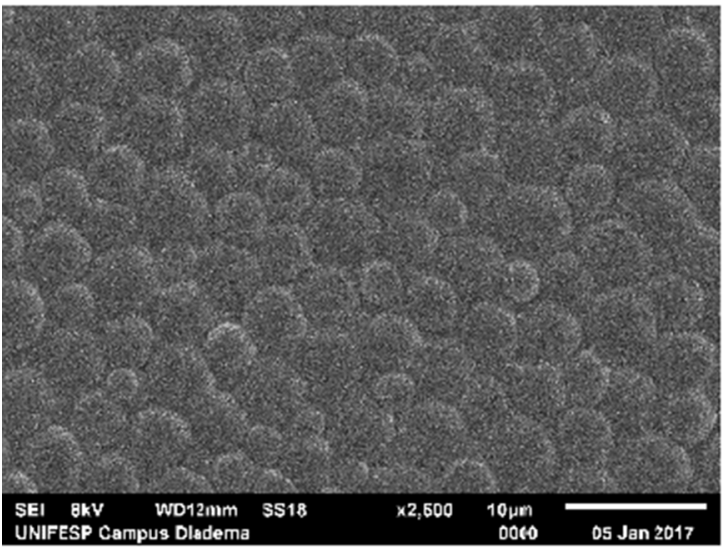

(c)

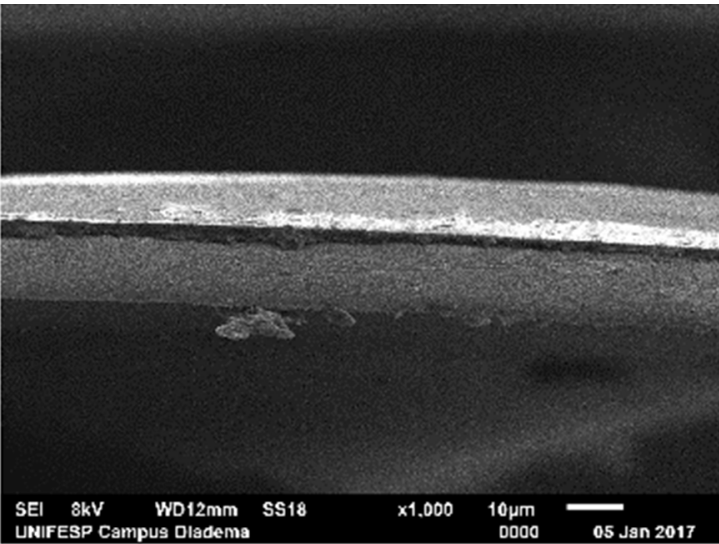

(b)

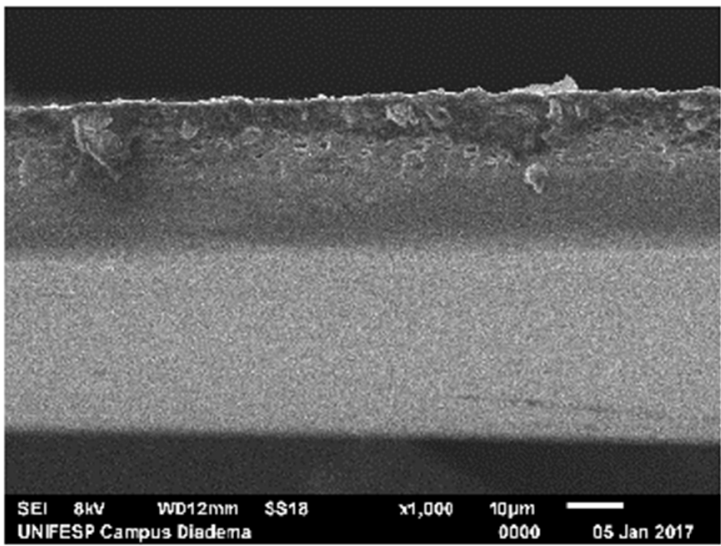

(d)

Fig. 1. SEM of membrane surfaces/section of membrane fracture (a) and (b) ALG + CS + HPMC + Sorbitol (F3); (c) and (d) Double layer membrane with the drug (F4).

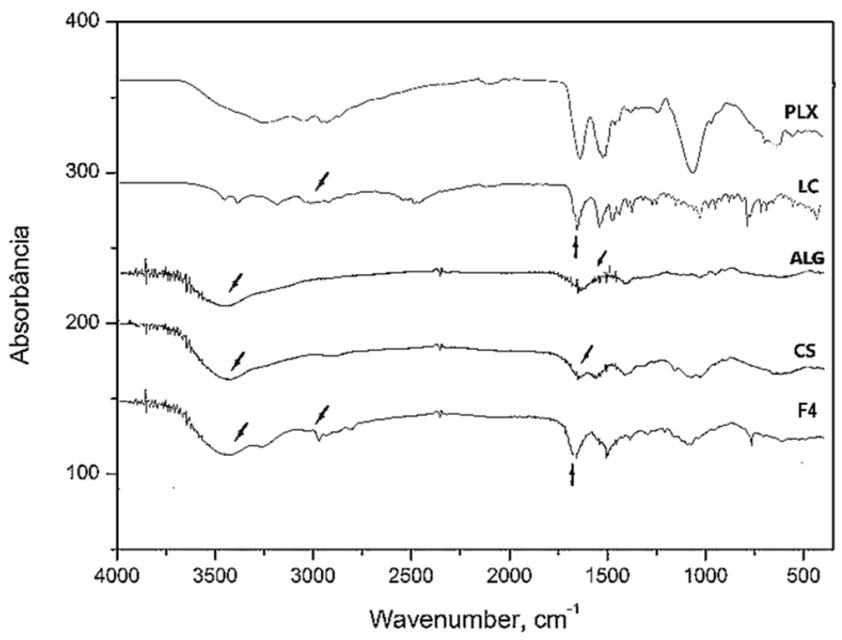

Fig. 2. FTIR spectra of lidocaine chloride (LC), polymyxin sulfate (PLX), sodium alginate (ALG), chitosan (CS), and double-layer membrane (F4).

sample spectra of the samples were similar as those reported in the literature (Wu et al., 2018).

The thermal analyses of the membranes were used to observe the interaction between the polymers, and to select the materials with the best thermal properties for specific uses. Fig. 3(a) shows the results obtained for the monolayer membranes composed by ALG (F1) and CS

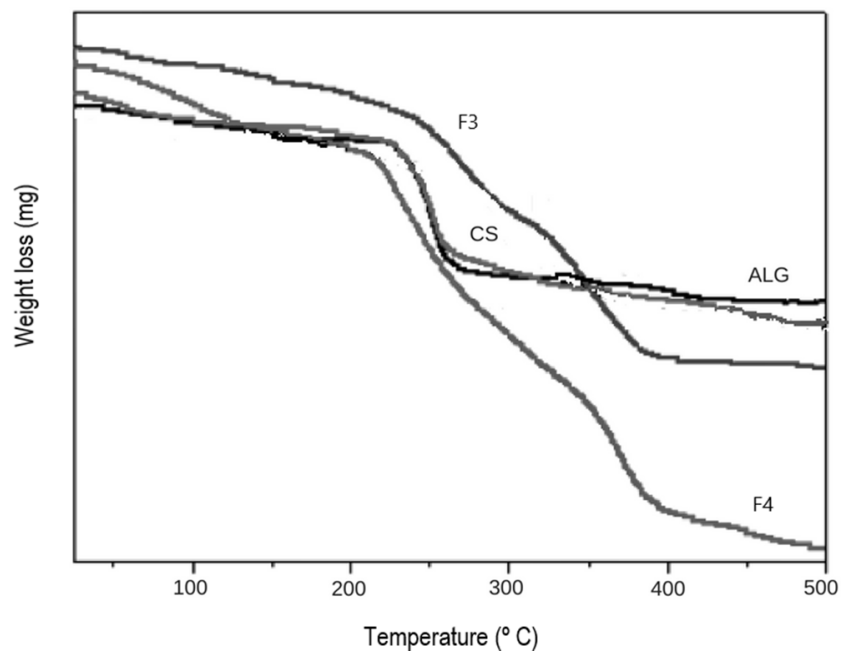

Fig. 3. Thermogram F1 (ALG), F2 (CS), F3 (ALG + CS + HPMC + sorbitol) and F4 (double layer).

(F2). Fig. 3(b) shows a double layer membrane without drug (F3) and a double layer membrane with the drug (F4). Thermograms provide information about three thermal events, the first one related to dehydration, and the third associated to the carbonization of the analyzed samples (Gallardo-Rivera et al., 2018; Lino et al., 2017). The membranes exhibited a loss of mass in different stages depending on their 
composition. The analysis was restricted to the probable interference of the presence of the drugs in the membranes.

In the double-layer membrane (F4) the mass loss started at $26.43{ }^{\circ} \mathrm{C}$, with a mass loss percentage of $100 \%$ for at $382.42^{\circ} \mathrm{C}$. It can be observed that the decomposition of the double layer membrane with drug presents only two thermal events, being more accelerated compared to the membrane without the drug (F3) that showed three events of mass loss. These evidence a change in the thermal stability of the set (membrane) with the addition of the proposed drugs, thus showing a probable interaction between the polymers, LCH and PLX.

The decay of LCH was in accordance to those reported by Pathak and Nagarsenker (2009). It occurred between $197{ }^{\circ} \mathrm{C}$ and $263{ }^{\circ} \mathrm{C}$ with endothermic peaks between $212{ }^{\circ} \mathrm{C}$ and $251^{\circ} \mathrm{C}$, similarly to PLX, with a thermal degradation with temperatures lower than those of the polymers involved in the sample. Thermal degradation at a lower temperature in these membranes suggests the complexation between CS and drug ions through the formation of ionic bonds between the polymers and is possibly associated with the loss of chain organization (Bigucci et al., 2008).

The increase in temperature favors the volatilization of the water and consequently an approximation of the polymer chains, and after evaporation of the water, a repulsion occurs between the positive charges of the chitosan and the positive charges of the drugs promoting the expulsion of these from the chain. An observation also happened in the study of (Lino et al., 2017) with CS hydrogels for nicotine release.

Fig. 4 shows the DSC profiles of F1 (ALG), F2 (CS), F3 (double layer without drug) and F4 (double layer with the drug). A change between F3 and F4 was observed confirming the presence of the anesthetic by the reduction of the intensity of the melting peak. The addition of PLX promoted an increased membrane crystallization as evidenced by the exothermic peaks of $\mathrm{F} 4$ at $140{ }^{\circ} \mathrm{C}$. The crystallinity of the membranes was changed by the presence of both drugs.

Mucoadhesion describes the bioadhesive bonding capacity that is established between a mucoadhesive polymer and the mucus layer onto the mucosal surface (Bassi da Silva et al., 2017). The mucoadhesion has been proposed as a way of prolonging the residence time of the product in a particular region, contributing to the increase of the therapeutic effect of the drugs. Thus, several materials with different bioadhesive characteristics aiming to increase adhesion to the mucous were proposed, among them: CS, ALG, and HPMC (Caramella et al., 2015). Table 2 shows the adhesion results of the membrane. The presence of drugs did not significantly alter the adhesion properties of the membranes. Moreover, CS and ALG have been previously described to

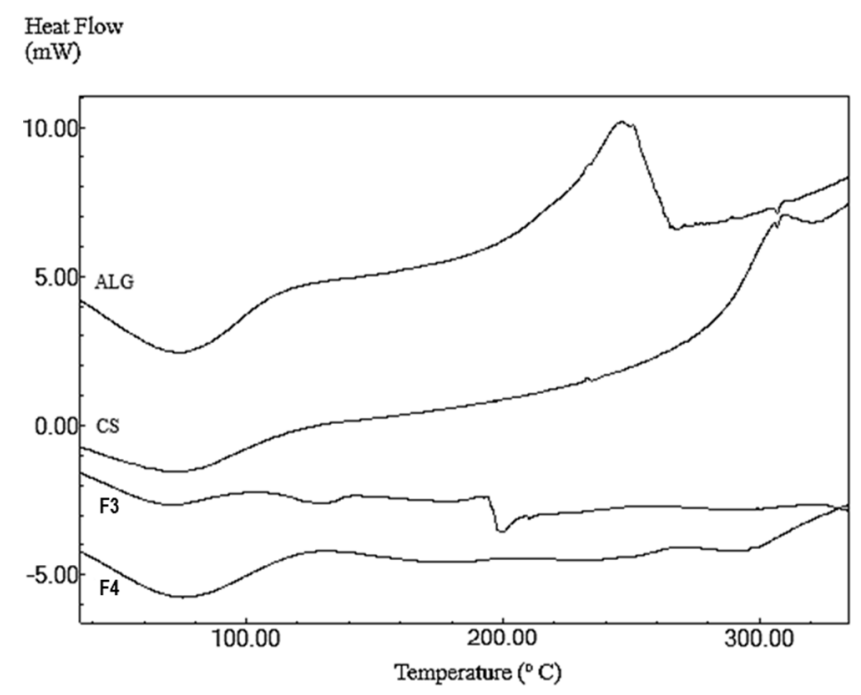

Fig. 4. DSC curves for membranes: ALG, CS, F3 (double layer without drug) and F4 (double-layer with the drug).
Table 2

Mean values of strength detachment and mucoadhesion.

\begin{tabular}{lll}
\hline Sample & Strength detachment $(\mathrm{N})$ & Mucoadhesion $(\mathrm{N})$ \\
\hline F1 & $2.679 \pm 0.282^{\mathrm{a}, \mathrm{b}}$ & $0.459 \pm 0.190^{\mathrm{a}}$ \\
F2 & $2.795 \pm 0.023^{\mathrm{a}, \mathrm{b}}$ & $1.001 \pm 0.258^{\mathrm{a}}$ \\
F3 & $2.915 \pm 0.242^{\mathrm{a}, \mathrm{b}}$ & $0.587 \pm 0.379^{\mathrm{a}}$ \\
F4 & $2.785 \pm 0.383^{\mathrm{a}, \mathrm{b}}$ & $0.842 \pm 0.206^{\mathrm{a}}$ \\
\hline
\end{tabular}

Mean \pm standard deviation of the replicates. Means with equal letters indicate that there is no significant difference $(\mathrm{p}<0.05)$ in the property studied according to the Tukey test.

possess mucoadhesive properties (Ahmad et al., 2018; GuadarramaAcevedo et al., 2019), thus excellent adhesion properties of our membranes were expected.

The carboxyl and hydroxyl groups of the polymers are responsible for the formation of hydrogen bonds with the mucus layer, however, when introducing additional components, the strength and the mucoadhesive properties can be modified. Cationic polymers, such as $\mathrm{CS}$, are excellent mucoadhesive materials, a property explained for the positive charge on their surface, being able to interact with the mucin negative molecules through electrostatic attraction (Frank et al., 2014). Anionic polymers, such as ALG, have carboxylic groups in their structure interacting through hydrogen bonding with oligosaccharides present in the mucin molecule, making up suitable adhesive materials (Khutoryanskiy, 2011).

The mechanical properties are a parameter with significant importance since natural polymers have several limitations when compared to the synthetic ones, such as low tensile strength, elongation at break and higher flexibility (Ahmad et al., 2018; Guadarrama-Acevedo et al., 2019). Table 3 shows the mechanical properties of F3 and F4 membranes. The thickness, elongation, Young's Modulus (MPa), and stress were evaluated. The F4 membrane exhibited higher stiffness and the greater force impressed at the moment of rupture (Tension) and better elongation compared to the F3 membrane. Statistically, the difference was significant when comparing them both. Instead, regarding to thickness, the difference was not statistically significant between F3 and F4 membranes.

The loading of the drugs intimately influenced the mechanical properties in the $\mathrm{F} 4$ membrane, which indicates the potential increase in the intermolecular interactions (hydrogen bonds) that contributes to the rigidity of the structure. According to the literature, CS-ALG membranes exhibit a tensile strength at break of about 6 to $31 \mathrm{MPa}$ (Bueno et al., 2014); both F3 and F4 (before and after drug incorporation), showed a the membrane tension was higher than the reported values. The tensile stress of the epidermis without injury is between 5 and $30 \mathrm{MPa}$. According to Bueno et al. (Bueno et al., 2014), an increase in skin tension in moments of physiological stress, such as the appearance of a wound, is already promoted by the body itself and favours the cellular migration of fibroblasts, primary cells in tissue repair, therefore a biomaterial with good rupture stress assists in the cicatrizing process.

Regarding the evaluation of the elastic properties of the membranes, there was a considerable increase in the values of the Young's modulus, assuming that the less flexible the material, the higher this value, it can

Table 3

Mechanical properties of F3 and F4 membranes.

\begin{tabular}{lllll}
\hline Membranes & $\begin{array}{l}\text { Thickness } \\
([\mathrm{mm}] \pm \delta \varepsilon)\end{array}$ & $\begin{array}{l}\text { Elongation } \\
(\% \pm \delta \varepsilon)\end{array}$ & $\begin{array}{l}\text { Young's } \\
\text { Modulus }(\mathrm{MPa}) \\
(\text { medium } \pm \delta)\end{array}$ & $\begin{array}{l}\text { Stress } \sigma[\mathrm{MPa}] \\
\text { (medium } \pm \delta \text { ) } \\
\text { Stress }\end{array}$ \\
\hline F3 & $0.025^{\mathrm{a}} \pm$ & $5.286^{\mathrm{b}} \pm$ & $1744.645^{\mathrm{b}} \pm$ & $80.580^{\mathrm{b}} \pm$ \\
& 0.006 & 0.160 & 1371.927 & 33.479 \\
F4 & $0.018^{\mathrm{a}} \pm$ & $8.286^{\mathrm{a}} \pm$ & $2923.338^{\mathrm{a}} \pm$ & $247.137^{\mathrm{a}} \pm$ \\
& 0.007 & 0.138 & 1163.253 & 119.482 \\
\hline
\end{tabular}

Different letters $(\mathrm{a}, \mathrm{b})$ in the same column indicate a significant difference (Tukey test at 95\% confidence). Each value represents the mean \pm S.D. $(n=3)$. 
be expected that the loading of both drugs to the membranes will promote an increase of elasticity. The Young's modulus indicates the hardness (rigidity) of the material when it is subjected to an external tension of tension, being the maximum tension those that the material supports without suffering any permanent deformation. Among the various characteristics of a dressing, maintaining its integrity during use is paramount. Therefore, the evaluation of this property is crucial to assist in the storage, handling, and application of the device. The modulation of the swelling forces promotes the improvement of polymeric biomaterials in several sectors, such as the food and pharmaceutical industries (Fernandes et al., 2017). The membranes F1, F2, and F3 did not remain intact when buried in phosphate buffer; the initial elevation can be explained considering that ALG and CS are polysaccharides with high hydrophilicity and, therefore, have a high absorbing capacity. This feature, at the primary stage of exposure to injured tissue, is essential for the application to exudative wounds. F4 membrane showed a high absorption in the second hour of immersion, reaching $63.3 \% \pm 0.00590$ of degree of swelling, remaining constant and reaching the chemical balance in the process. The swelling is indeed considered the first stage of the mucoadhesion process and, in the presence of moisture, the polymers initiate contact with the mucosa, providing mechanical entanglement and formation of hydrogen bridges and/or electrostatic interactions between the polymer and the mucous network (Szekalska et al., 2017).

Cell viability of the membranes was determined using an indirect method. Cell viability results (Fig. 5) show that membranes without the drug (F3) do not present a toxic effect, but not the membranes with the drug (F4). For the purpose of applying the membranes as controlled release systems, they must show no or very limited toxicity levels. Bueno et al. (Bueno et al., 2014) studied porous membranes of CS and ALG, showing that there were no adverse effects on cell growth. The observed cell viability reduction is related to PLX inherent toxicity, already reported in several studies. The toxicological risk of using PLX is attributed to systemic distribution upon intravenous administration, being nephrotoxic in the long term. There is however a great difficulty in determining the real involvement of this drug in renal injury, because patients receiving PLX treatment do show several other factors that contribute to the nephrotic dysfunction (Brandenburg et al., 2012).

The interaction between cells and artificial materials can occur

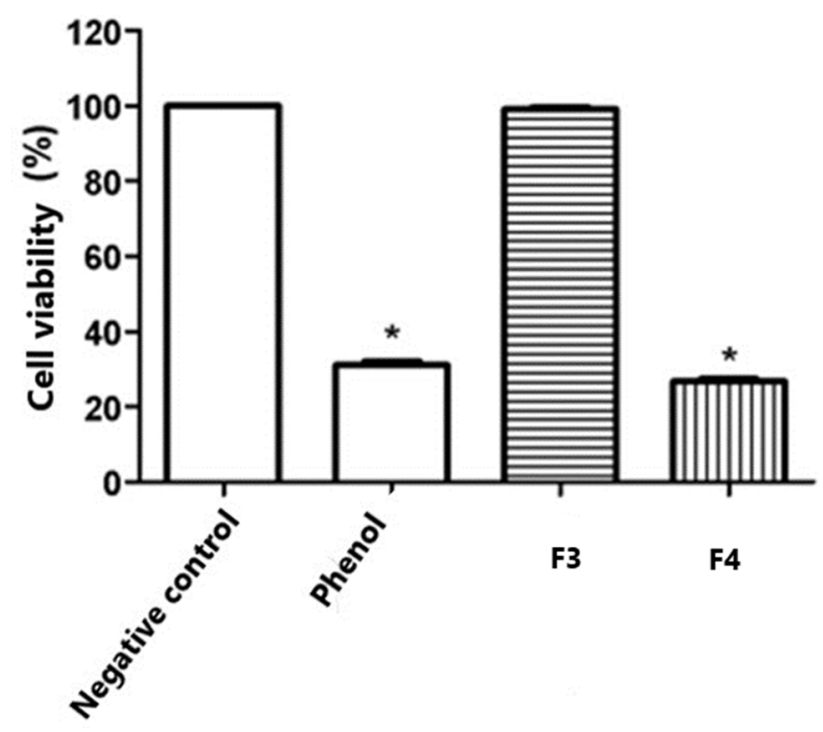

Fig. 5. Effect of drug-free (F3) and drug (F4) double-layer polymer membranes on the viability assessment of human L929 fibroblasts determined by the MTT assay after $24 \mathrm{~h}$ of incubation. The negative control was treated with the vehicle used to dilute the drug (DMSO 5\%) and as positive control: $0.02 \%$ phenol. The data correspond to the mean \pm S.P.M. of four independent experiments. directed through extracellular matrix ligand molecules or only through chemical bonds, such as hydrogen bonds between the cell membrane and polymer functional groups. However, this latter type of interaction does not favour the adhesion that cells require to survive. The attribute results from the ability in which the biomaterial adsorbs extracellular matrix molecules from the extracellular medium (either from in vitro culture medium or from body fluids in vivo). Efficient adsorption depends on several factors associated with the material surface: hydrophilicity/hydrophobicity, electric charge, topography, mechanical properties, crystallinity, porosity, solubility and the presence of specific functional groups (Othman et al., 2018).

The membranes used for the adhesion test were fixed, as described in the methodology, and the surface was evaluated by SEM images (Fig. 6). Due to the double-layered nature of these membranes, the analysis was performed on both sides as follows: Side A and B belonging to F4 membrane (Side A: ALG-PLX; Side B: CS-LC-PLX) and sides C and D (Side C: ALG and Side D: CS-HPMC-sorbitol) belonging to F3 membrane.

The results show a significant difference between the adhesion of the membrane F4 and F3. On both sides of the drug membrane (F4), the most star-shaped cells proliferated and adhered around and between the pores of the membranes over the biomaterial. On the surface of F3, the observed differences that can be associated with polymers on both sides. On side $\mathrm{C}$ we have pure ALG, and almost no ordered cell activity or even distributed between the pores, in contrast to side D, where is CS alone and where cell adhesion is more significant with more clustered and shaped cells rounded.

It is known that a cell with strong adhesion properties is in an extended form and spreads over a larger area. In contrast, when adhesion is incipient, the cell adheres with a rounded shape, showing a minimal contact zone between the cell and the substrate; since most cells require adherence, they hardly survive under these conditions. When the adhesion force is higher, the contact area between the cell and the substrate is larger, forming multiple adhesion points, evolving to the proliferative phase and consequent differentiation.

The antimicrobial activity of the samples is directly linked to their potency to inhibit the growth and multiplication of the microorganism in the presence of a presumed concentration of a tested antimicrobial agent.

The obtained MIC values for Pseudomonas aeruginosa and Staphylococcus aureus are promising results since they presented the same concentration values. The data for Staphylococcus aureus showed a MIC similar to that of Pseudomonas aeruginosa for CS of $7.8 \mu \mathrm{g} \cdot \mathrm{mL}^{-1}$, being the lowest concentration tested, thus confirming the antimicrobial activity previously described in the literature (Insua et al., 2017). The MIC value recorded for PLX against both strains was $292.9 \mu \mathrm{g} \cdot \mathrm{mL}^{-1}$. ALG did not show any antimicrobial activity $\left(0 \mu \mathrm{g} \cdot \mathrm{mL}^{-1}\right)$ on both Staphylococcus aureus and Pseudomonas aeruginosa strains, thus suggesting no action in its pure form. However, when associated with PLX, it establishes a promising mechanism of inhibition, reaching a MIC value of 148.4 $\mu \mathrm{g} \cdot \mathrm{mL}^{-1}$. All constituents of the $\mathrm{F} 4$ double-layer membrane have their antimicrobial properties recognized in the literature (Severino et al., 2015, 2017). For the double-layer membrane containing the drug PLX (F4), the MIC value was $144.5 \mu \mathrm{g} \cdot \mathrm{mL}^{-1}$ against both strains. The action of CS is established by the mechanism of interfering with bacterial metabolism by interacting the polymer molecules on the cell surface or acting by penetrating the membrane of the microorganism and then adsorbing into DNA molecules by blocking the transcription of RNA to DNA (Wang et al., 2017).

Fig. 6 shows that the double-layer membrane containing the drug PLX (F4) presented an inhibition halo for the strains tested, demonstrating that even the drug incorporated in the membrane had no loss of its antimicrobial activity. In contrast, this action was not observed in F3, which was not able to form a halo, corroborating the data recorded for the MIC testing. It should be noted that the absence of inhibition halo does not imply a complete antimicrobial inactivity, since the obtained membranes were able to prevent the growth of the tested 

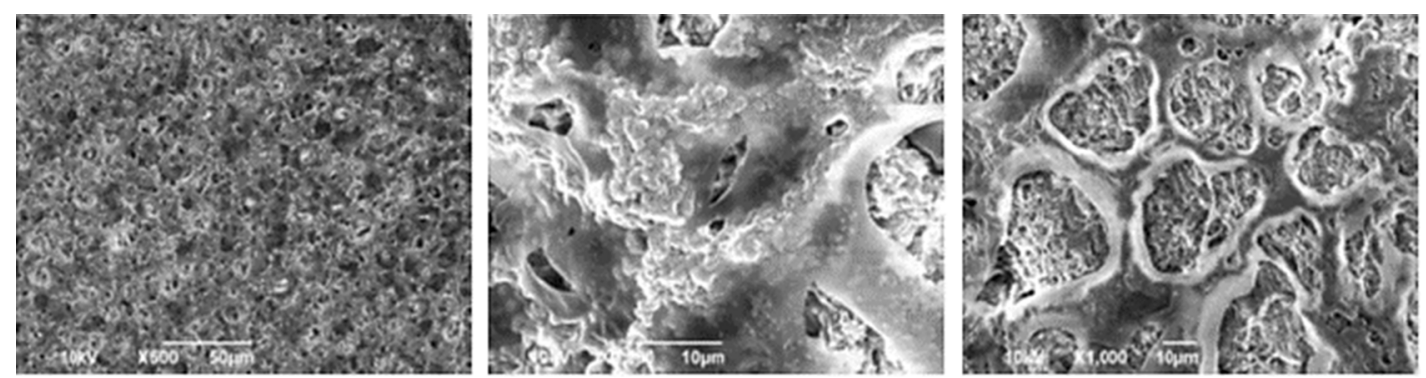

A
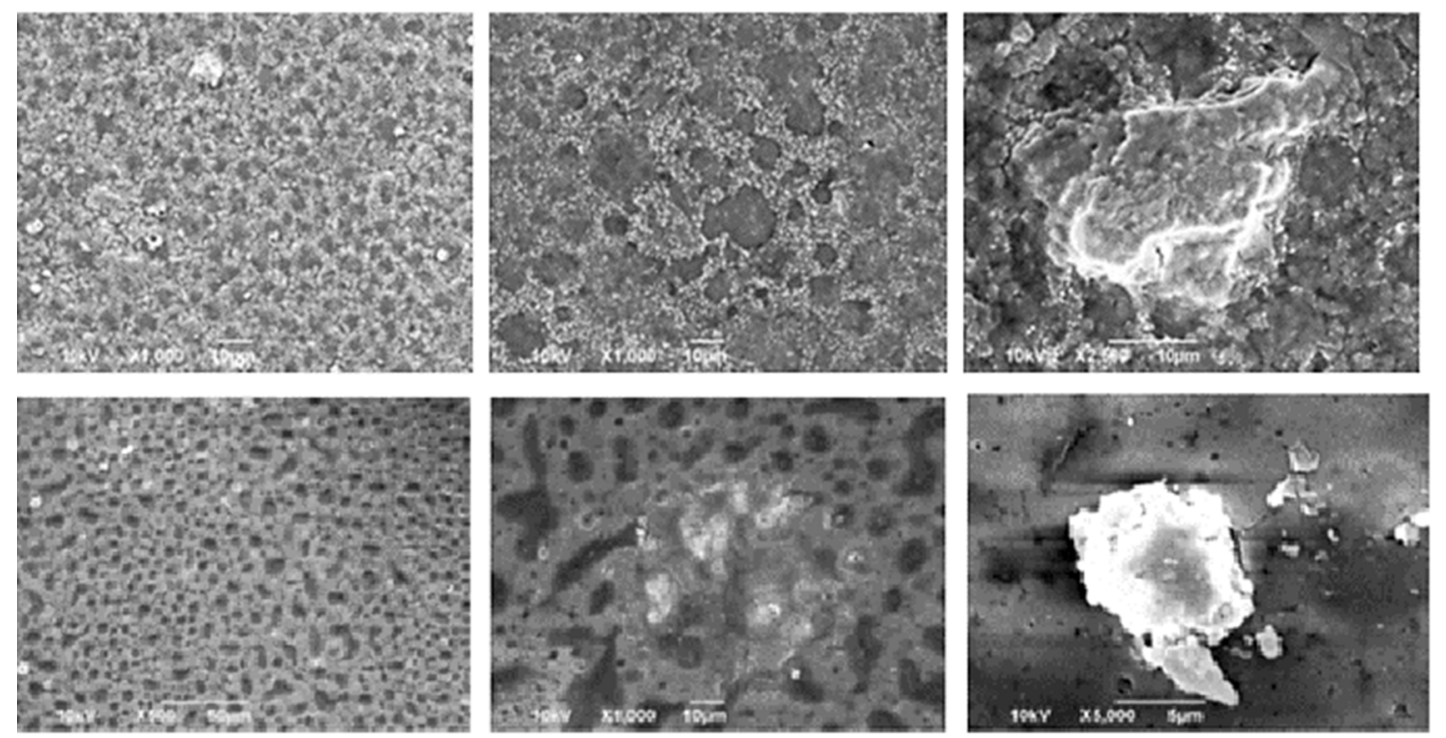

$\mathrm{C}$
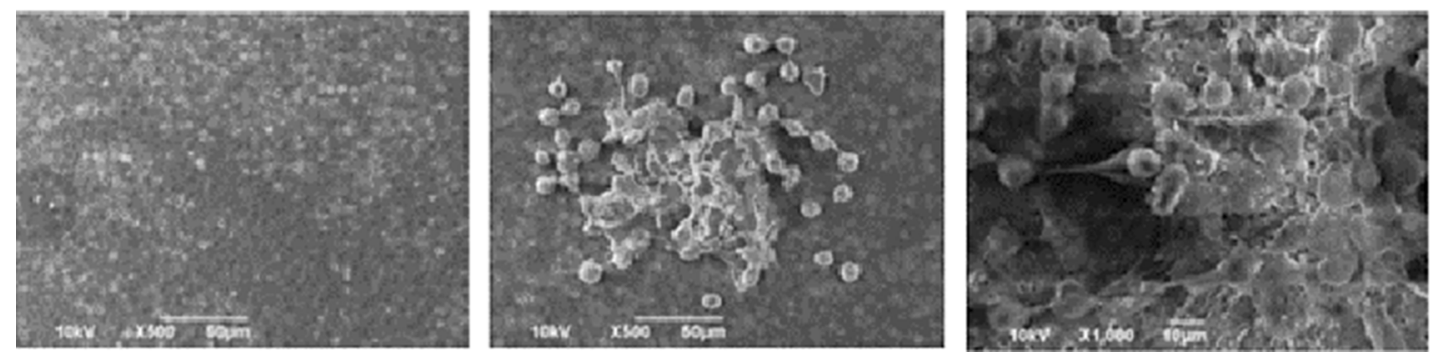

$\mathrm{D}$

Fig. 6. SEM after adhesion of L-929 cells for $48 \mathrm{~h}$. Sides A and B belonging to membrane F4 (Side A: Sodium Alginate with Polymyxin B Sulphate; Side B: Chitosan with Lidocaine Chloride and Polymyxin B Sulphate) and Sides C and D for F3 Membrane (Side C: sodium and Side D: Chitosan, HPMC and sorbitol).

microorganisms on their surfaces, which would make this biomaterial a candidate to act as a barrier against microorganisms (Fig. 7).

In this study, animal healing experiments were performed using an in vivo biological model selected due to its easy acquisition, handling, accommodation, resistance to surgical aggression and the low mortality presented in the infectious processes. Rat adults males were chosen in order to avoid hormonal variations of the female cycle that could interfere in the tissue repair mechanism (Mendes and de Jesus Souza, 2017). Evaluation of the macroscopic aspect of wounds over time has been systematically performed in experimental studies to guide the most appropriate therapy (Zeugolis et al., 2018). Fig. 8 shows all group no signs of purulent exudation with no abscess formation in the inflammatory repair phases (03-07 days), and no deformed scars in the later stages (14-21 days). These data suggest that the healing process occurred uneventfully during the tests and that the developed biomaterial seems adequate to be used as a wound dressing (Song and Salcido, 2011). No signs of self-aggression orbiting of other animals on the bloody area were observed, which also seems to suggest that the manipulation of the animals did not produce stress that interfered with their behaviour after performing the experimental procedures.
The evaluation of the wound retraction index (WRI) over the 21 days of study is shown in Fig. 9. At day 3, the WRI of the control group (22.0 $\pm 1.79)$ was statistically similar to $\mathrm{F} 3(22,34 \pm 0.24)(\mathrm{p}>0.05)$. However, F4 had a significantly higher index in both groups (14.85 \pm 1.16) ( $\mathrm{p}<0.001)$. At day 7, the FRI presented by the F3 group ( $85.98 \pm$ $0.04)$ was significantly higher than control $(37.75 \pm 3.26)$ and $F 4$ (35.14 \pm 0.63$)(\mathrm{p}<0.001)$, but there was no significant difference between the last two ( $\mathrm{p}>0.05$ ). After 14 days, the WRI obtained in groups F3 (92.10 \pm 061$)$ and F4 (90.55 \pm 0.09$)$ was significantly higher than in control $(80.56 \pm 3.98)(\mathrm{p}<0.001)$, but there was no difference between the two membranes tested ( $\mathrm{p}>0.05)$.

Physiologically and in an orderly and efficient manner, wound heal is characterized by four distinct but overlapping phases, namely: hemostasis, inflammation, proliferation, and remodelling. This complex process needs to be tightly regulated to create a balanced molecular environment that allows healing (Olczyk et al., 2014). Regulation is based on various growth factors and cytokines that make up a complex signalling network that alters target cell growth, differentiation, and metabolism (Garcia-Orue et al., 2017).

The F3 membrane (without drugs) presented better WRI during the 
Bacteria

Staphylococcus

aureus

Pseudomonas

aeruginosa
Non-drug double layer

membrane (F3)
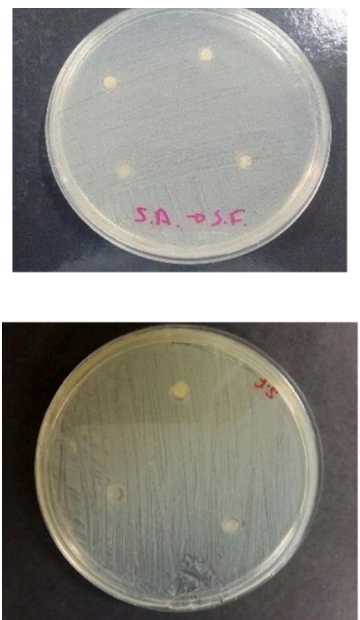

Double layer membrane with

the drug (F4)
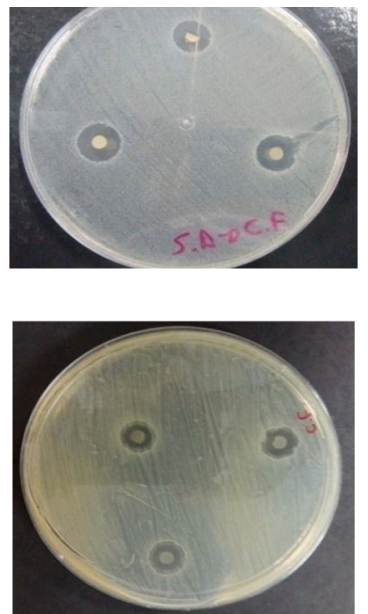

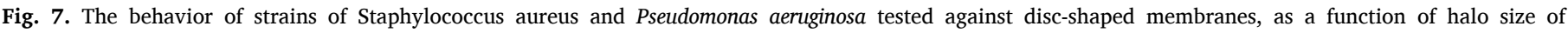
growth inhibition.

Days

$\mathbf{0}$
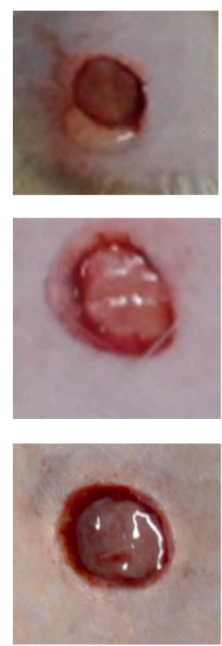

3
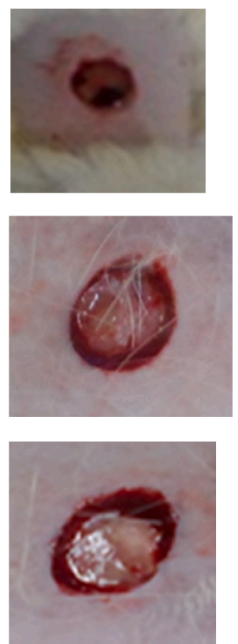

7
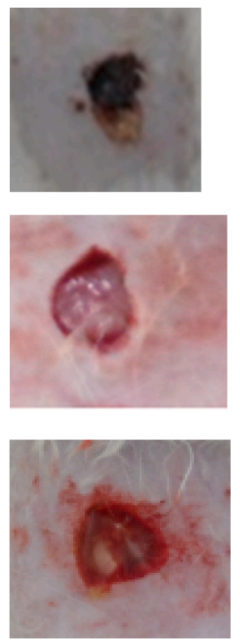

14
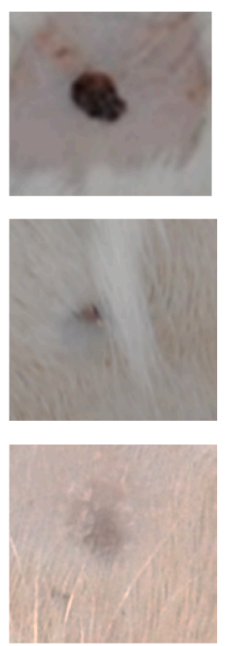

21
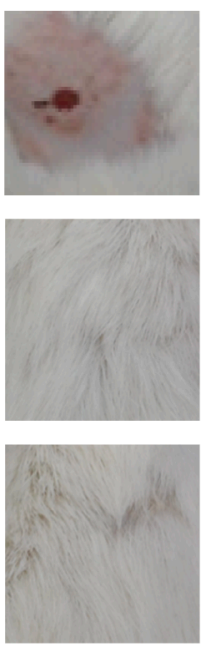

CTR

F3

F4

Fig. 8. Macroscopic evaluation of the healing activity of F3 and F4 membranes in models of rat skin wounds over 21 days of the experiment.

initial repair phase (on days 3 and 7), which was positive, considering that the development of this product modality is intended to be used for wound healing over all the distinct phases (Fig. 9a). Primary area where there is a high level of exudate and consequent formation of interstitial oedema, suggesting that among the polymeric components composing the membrane, there are anti-inflammatory properties that should be considered.

CS dressings can accelerate the wound healing process through macrophage activation, increased number of fibroblasts, action on cell differentiation, and skin reepithelialisation (Debone et al., 2019). Upon hydrolysis, this biopolymer releases $\mathrm{N}$-acetyl- $\beta$-D-glycosamine oligomers which, when incorporated into extracellular matrix glycoproteins, activates these properties, stimulating and modulating the synthesis of natural hyaluronic acid which plays an essential role in the morphogenesis and inflammation process, promoting higher cell motility, adhesion, and proliferation. ALG is widely used in the production of dressings intended primarily for the management of exudative wounds, promoting absorption by ion exchange between the product and the exudate, resulting in the formation of a gel capable of maintaining a moist environment suitable for tissue granulation (Muzzarelli, 2009). Several studies have worked with associated CS and ALG dressings as blends, alone, or even as drug delivery systems and growth factors, helping in the positive evolution of tissue repair of several types of lesions (Bui et al., 2017; Gallardo-Rivera et al., 2018; Liu et al., 2018).

On the other hand, the fact that the results observed in group F3 were more expressive than in F4 in the initial healing phases suggest the chemical modification of the membrane with their addition (Fig. 9b), as already seen in the previous characterizations. The use of topical antimicrobials in uninfected wounds is still matter of intensive study; according to Han and Ceilley (2017), they may delay the inflammatory phase. The indication for topical antibiotics is a clinically infected wound with purulent drainage, erythema, heat, pain, tenderness and/or hardening. Recent studies with the routine administration of antibiotics have led to better results, but often resulting in patient discomfort, along with the possibility of antibiotic resistance and contact dermatitis.

The F4 membrane is designed for wound with a more difficult heal 


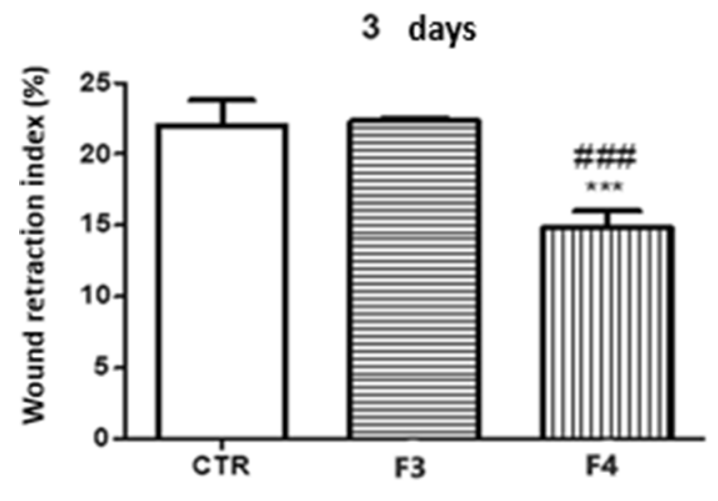

$\mathbf{A}$

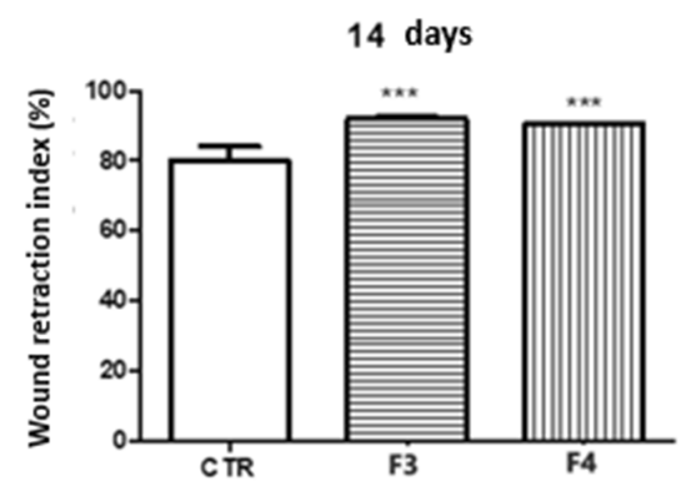

C
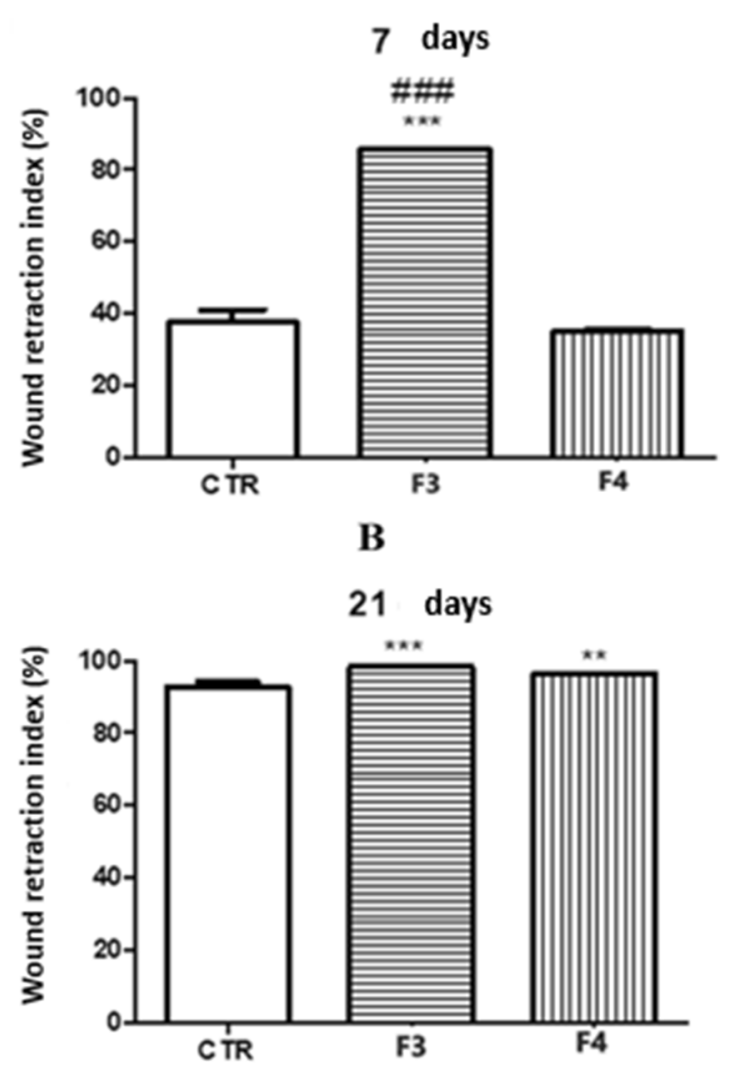

D

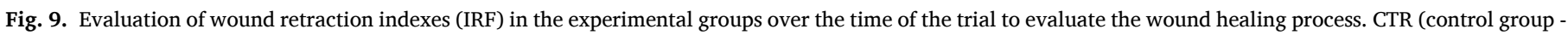
uncoated wound), F3 (drug-free membrane-covered wound), F4 (drug-layered double-membrane wound).

process, e.g. those that are already infected or potentially contaminated due to manipulation or even biomechanics of the lesion, such as burns, skin trauma in environments or caused by contaminated objects, animal bites and scratches, vasculogenic ulcers, among others. This aim is reinforced by the evidence shown in Fig. 9(C and D) which corresponds to the final healing stages at days 14 and 21 , when this bioproduct has achieved satisfactory WRI for such application.

Han and Ceilley (2017) reinforce that under many conditions, the use of prophylactic antimicrobials in wounds is sometimes necessary, as the terms mentioned in the previous paragraph. A new study demonstrates that microbiota, involving one or multiple species of the microorganisms present and propagating within the wound, is the leading underlying cause of chronic wound pathogenesis. Also, drug release dressings are favoured over traditional dressings because of their direct or indirect effects. Wound site antibiotic administration options are more effective, overcoming some of the disadvantages associated with systemic antibiotic administration (Naseri-Nosar and Ziora, 2018).

From day 7 to day 14 , the formation of granulation tissue was observed, with the high levels of TGF- $\beta$ (Growth Transformation Factor) determine the beginning of active myofibroblastic differentiation in the scar area (Song and Salcido, 2011), to promote future contraction of the wound. After about 2-3 weeks, there was a remodelling where the collagen type is restored to usual (type I rather than type III) and the tissue matures. In our study, from day 14 onwards, the evolution of WRI in the F4 group was significantly higher than in the inflammatory phase, and both membranes (with and without drug) obtained an WRI statistically higher than the control group, suggesting that their use constitutes an advantage to the progress of healing.

The histomorphological characteristics associated with the inflammatory/reparative process and collagen deposition, were analysed by haematoxylin/eosin (HE) and Picrosirius staining, and observing criteria established after a survey of the specialized literature by the Sultana et al. (2009) were adapted for this study and presented in Table 4.

Scores 1 and 2 were discussed together and are shown in Fig. 10 below. In both, the maximum score reflects the absence of the measured data, that is, when scored with 4 , for example, that area was observed without granulation tissue (score 1) and without inflammatory infiltrate (score 2). Fig. 10A shows the presence and amount of granulation tissue evaluation. Over the three days of repair, statistical difference were observed between the group F3 and the control group $(p=0.0102)$ and also F3 in relation to F4 ( $\mathrm{p}=0.0062)$, which statistically resembles CTR ( $\mathrm{p}=0.9829$ ), a fact that is repeated when we observed the evolution over seven days of experiment, but with a greater presence of granulation in F3 compared to the three days. At day 14, no significant difference was observed between all groups (CTR vs F3: $p=0.8564$; CTR vs $\mathrm{F} 4: \mathrm{p}=0.8564$; F3 vs F4: $\mathrm{p}>0.9999$ ), which is repeated at day 21 (CTR vs F3: $\mathrm{p}=0.6515$; CTR vs F4: $\mathrm{p}=0.9829$; F3 vs F4: $\mathrm{p}=0.7596$ ).

Fig. 10B shows the intensity of inflammatory infiltrates over the days of the experiment. On day 3, no statistical difference was seen between all groups, showing an intense inflammatory activity, characteristic of this initial phase (CTR vs F3: $p=0.5200$; CTR vs F4: $p=0.7464$; F3 vs

Table 4

Evaluated parameters for healing score calculation.

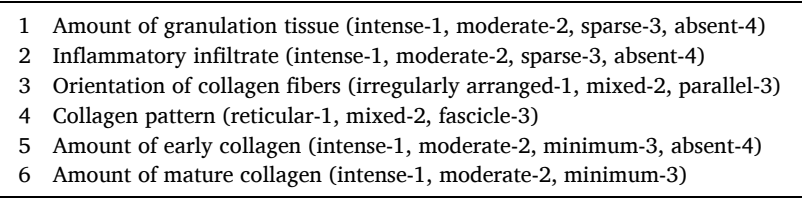

Scores 1 and 2: HE; scores 3-6: Picrosirius. 

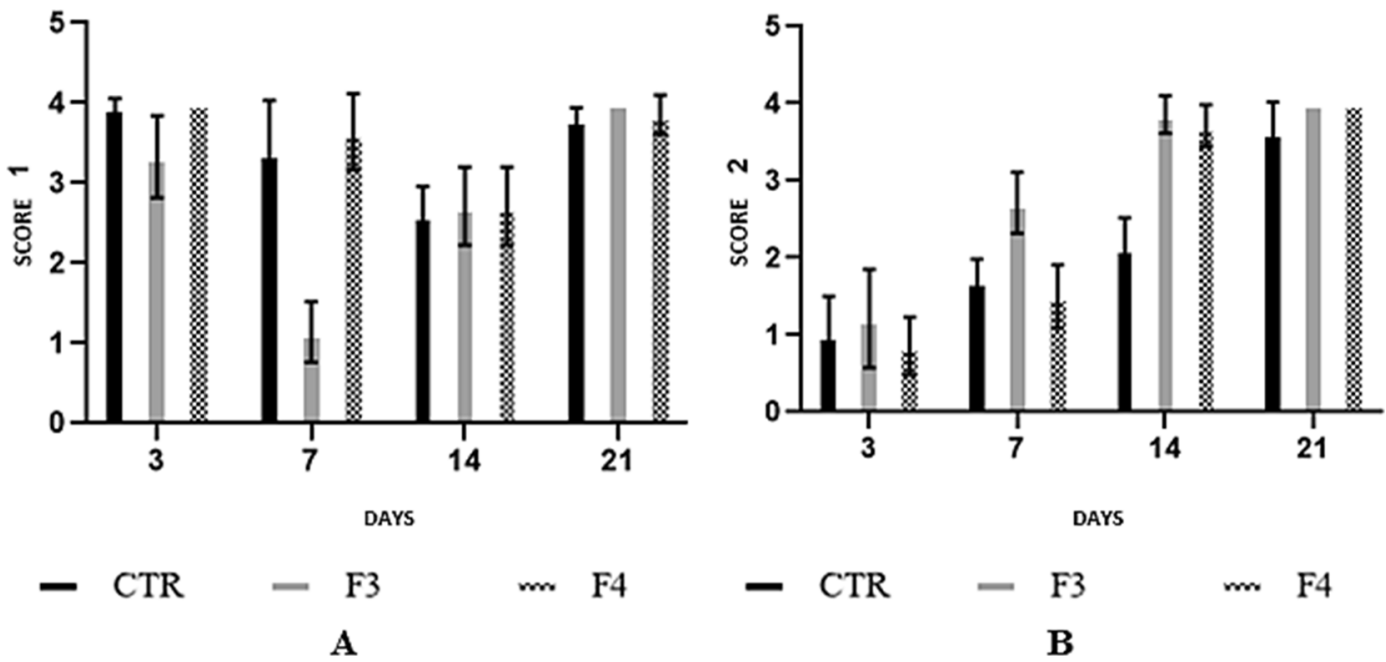

Fig. 10. Distribution of values for Histological Analysis Scores 1 and 2 by the group surveyed during the 21 days of the experiment. A) Quantification of granulation tissue (intense-1, moderate-2, sparse-3, absent-4) with early evolution to F3 and later F4 equalization compared to F3. B) Inflammatory infiltrate (intense-1, moderate-2, sparse-3, absent-4) demonstrating a slower F4 exit from the early (acute inflammatory) stages of healing and later equalization with F3 within 14 days.

F4: $\mathrm{p}=0.1685)$. At day $7, \mathrm{~F} 3$ stands out with a marked reduction in inflammation about the CTR group and F4 ( $<<0.0001)$. At day $14, \mathrm{~F} 4$ also presented a reduction in infiltrate, being similar to $\mathrm{F} 3(\mathrm{p}=0.7464)$ and both different from the CTR group, which remains with a moderate inflammation process $(\mathrm{p}<0.0001)$. At day 21 , all groups showed an absent and/or minimal inflammatory pattern, with no statistical difference between them.

The histological analysis showed the expected physiological events

$$
\text { CTR }
$$

Days

3

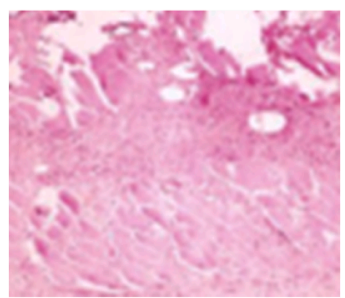

7

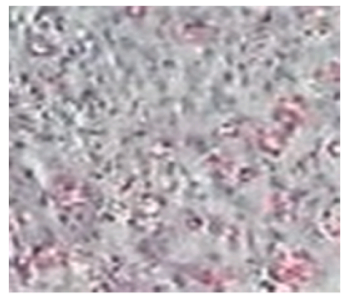

14

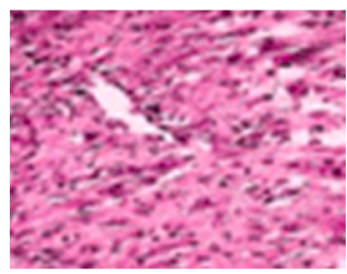

21
F3
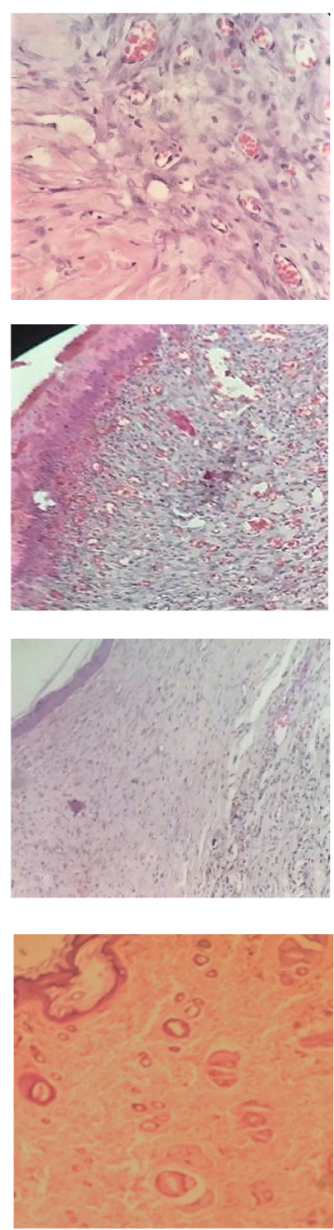

F4
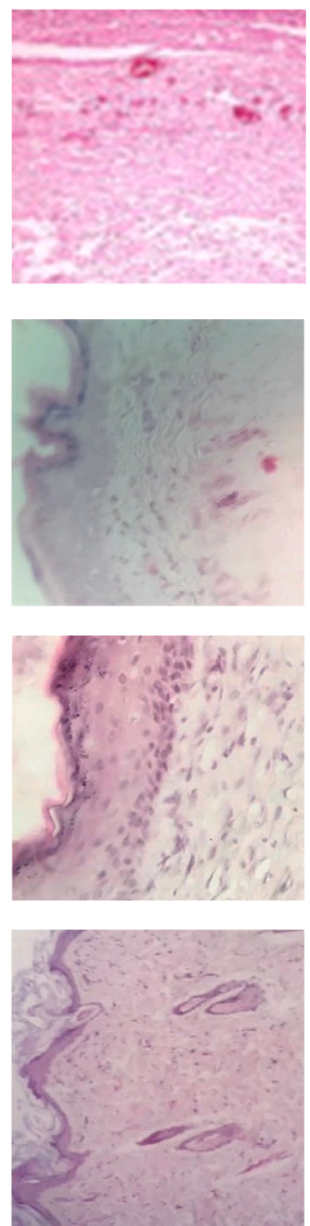

Fig. 11. The histological sections (HE) of the groups (wounded areas) over time of the biological wound healing trial, where CTR (control group), without coverage; F3 - membrane without drug; F4 - membrane with the drug; Intense neutrophilic infiltrate is visualized at three days, and granulation tissue at seven days. At 14 days, replacement of granulation tissue with a primary fibrous scar is seen in all groups. At 21 days the fibrous scar tissue is denser at F3 and F4. Characteristics of the dermal epithelium with formation of dermal appendages only observed in membrane-treated wounds. 
of the healing process in each period (Fig. 11). The statistical differences observed in HE histology reflect the physiological evolution observed in scar retraction, where the drug membrane (F4) shows a different development compared to F3. The wounds treated with F4 showed higher inflammatory density than the others, including the presence of intense infiltration at seven days of the experiment.

As the structural difference between the membranes in the presence of drugs, PLX, and LC, the justifications for such prolongation of acute inflammation may lie in these. The effect of LC has been studied together with other local anesthetics under wound healing. Kesici et al. (2018) and Waite et al. (2010) reported that the drug in question did not cause favourable and/or unfavourable changes in the healing of lesions in its inflammatory phase. With PLX, the literature states that, like most topical antibiotics, it promotes slight toxicity on cell migration during healing, especially on the polarization of keratinocytes that will restore the epithelial barrier (Brothers et al., 2015).

PLX also shows chemical structure with a fatty acid at its end which may suggest some interference with the healing process, given that the modulation of the inflammatory response by fatty acids in healing is not yet well established. Studies address the benefits of these substances, such as accelerating the inflammatory phase and stimulating new vessel formation (Rodrigues et al., 2016) while others point out negative aspects such as delayed healing due to prolonged maintenance of the inflammatory phase (Turk et al., 2013).

At day 14, F4 evolves reaching F3 in the proliferative or maturation phases, not differing significantly from each other. The same result is observed at day 21 when the maturation phase predominated in both groups. The recommendation for the use of F4, already made in this study, for colonized lesions or with high potential for infection (associated with the cause or another factor, such as patient immunosuppression), corroborates the literature stating that the use of topical antibiotic therapy should be restricted to the cases mentioned.

Scores 3 and 4 begin the assessment with picrosirius staining and are shown in Fig. 12. Both refer to the structure of presentation of collagen fibers in orientation (irregularly arranged-1, mixed-2, parallel-3) and standard, respectively (reticular-1, mixed-2, fascicle-3). Regarding the orientation of the fibers (Fig. 12A), the groups F3 and F4 (p = 0.0311) with F3 are already statistically different at the three days of repair, alternating with the organization of the collagen fibers and F4 still irregularly arranged. At seven days, F3 is already mixed and CTR and F4 continue with an irregular pattern regarding the measured score, with no statistical difference between the last two (CTR vs F3: $\mathrm{p}=0.0012$; CTR vs F4: $p=0,7776$; F3 vs F4: $p=0.0065$ ). At 14 and 21 days, the groups had no significant difference, migrating orientation at the end of the analyzed repair period to the parallel organization of their fibers.

Score 4 (Fig. 12B) showed that F3 was statistically significantly different from both the control $(\mathrm{p}=0.0006)$ and $\mathrm{F} 4(\mathrm{p}=0.0006)$ groups in the initial three days. F4 statistically resembles the CTR group ( $\mathrm{p}=$ $>0.9999$ ). In seven days, F3 and F4 have already matched ( $p=0.0932$ ). At day 14 and day 21, F3 and F4 remain statistically similar, reaching the fascicular pattern at the end of the analyzed period, differing from the CTR group that remained with a mixed collagen pattern.

Scores 5 and 6 , also analyzed with picrosirius, reflect the indirect quantification of early (type III collagen) and mature (type I collagen) collagen of the analyzed slides within 21 days (Fig. 13). The scoring pattern follows as intense-1, moderate-2, minimum- 3 , absent- 4 , the latter not being considered for score 6 . Under statistical analysis, the groups differed in the initial repair phases, 3 days, where we can observe the presence of early collagen (score 5 - Fig. 13A) at the beginning of F3 healing, in contrast to the other groups, between F4 and control group there was no significance (CTR vs F3: $\mathrm{p}<0.0001$; CTR vs F4: $\mathrm{p}=$ $>0.9999$; F3 vs F4: $p=<0.0001$ ). At 7,14 and 21 days there was no difference between the groups, physiologically evolving the healing process regarding the quantitative measurement of early collagen.

Type I collagen deposition was assessed using score 6 (Fig. 13B). The drug-free membrane, F3, showed the early presence of mature collagen with difference for F4 and CTR ( $\mathrm{p}<0.0001$ ) at three and seven days. At day 14 , both membranes were moderately mature and statistically similar $(\mathrm{p}=0.3497)$ with a difference for the control group ( $\mathrm{p}=$ 0.0008 ). At day 21, the presence of type I collagen in F3 and F4 was already assessed as intense ( $p>0.9999)$, unlike CTR $(p=0.0008)$.

The collagen deposition, were observed, which indicated that the physiological events expected at each healing phase were adequate (Fig. 14). At three days, there were greenish/yellowish-green collagen type III fibrils, of varying sizes present in all groups, but in F3 there was a visually better evolution of fiber organization, from the reticular to the mixed pattern. Groups F4 and CTR showed reticular and small amounts of arrangement (Fig. 14).

At seven days, the statistical difference between F3 and F4 still prevails, with the advance in the healing stage of the group treated with the drug-free membrane (F3). In general, considering the amount of collagen and its fiber disposition, there is a better healing evolution of the treated groups to the control group.

Alsarra et al. (2002) reported that CS stimulates, in the early stages of healing, the migration of inflammatory cells, growth factors resulting in angiogenesis and formation of earlier granulation tissue. However, the delay in the resolution of the inflammatory process of F4, already justified by the presence of PLX, results in decreased migration and
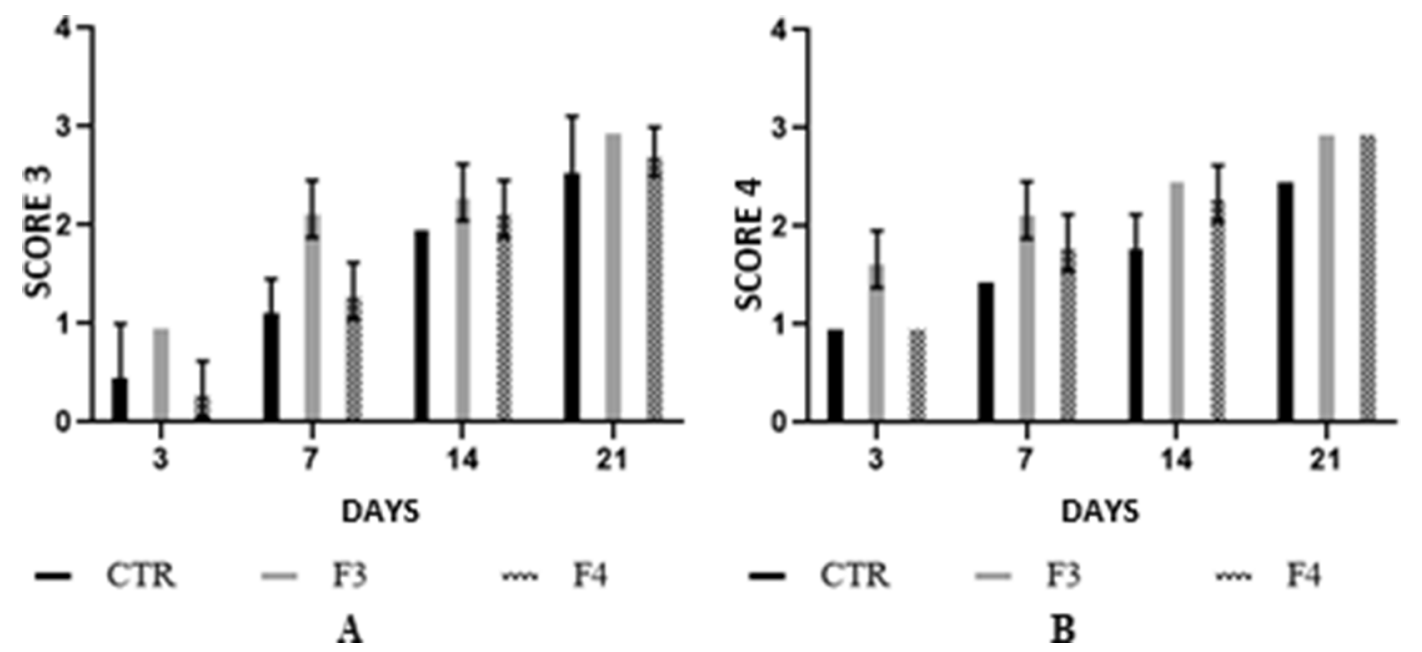

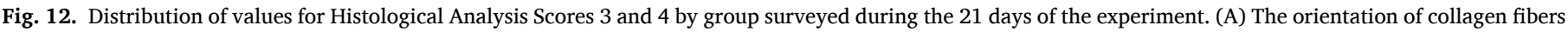
(irregularly arranged-1, mixed-2, parallel-3). (B) Collagen pattern (reticular-1, mixed-2, fascicle-3). 

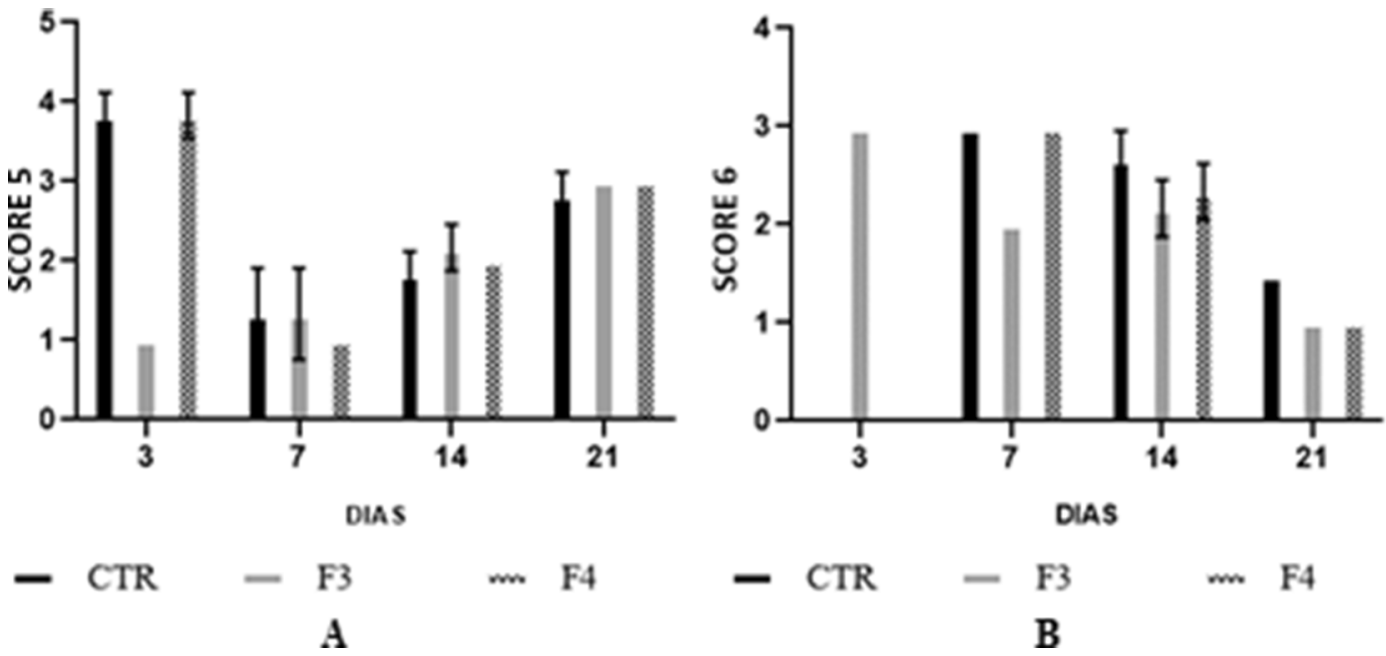

Fig. 13. Distribution of values for Histological Analysis Scores 5 and 6 by the group surveyed during the 21 days of the experiment. (A) Amount of early collagen (intense-1, moderate-2, minimum-3, absent-4). (B) Amount of mature collagen (intense-1, moderate-2, minimum-3).

CTR

Days

3

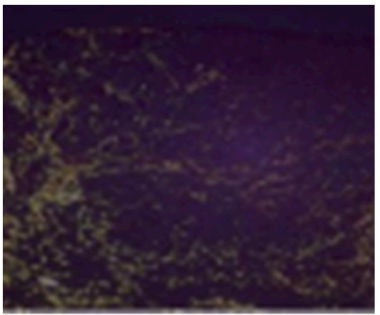

7

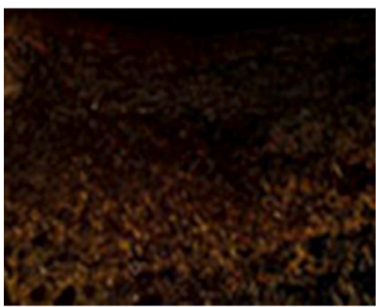

14

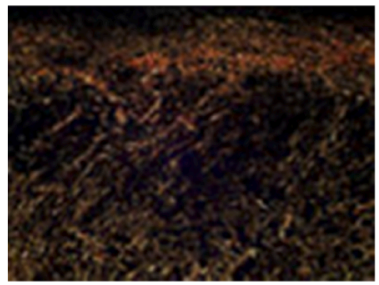

21
F3
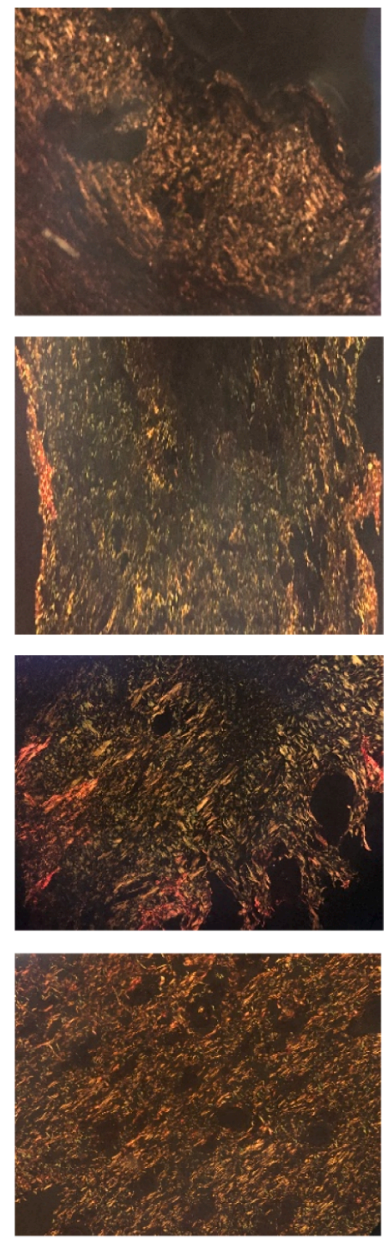

F4
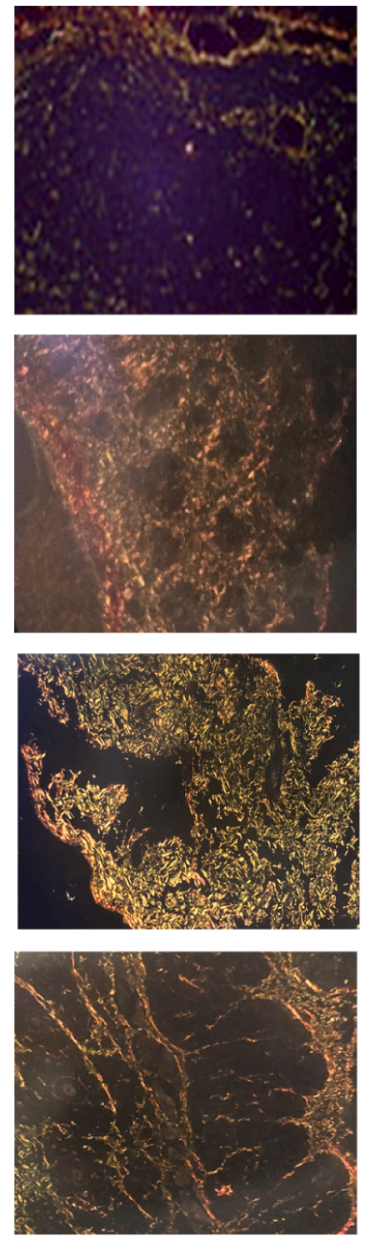

Fig. 14. Collagen deposition in experimental groups during 21 days of study. Days three and seven with predominance of thin type III (greenish/yellowish) collagen fibers in F4 and CTR, while in F3 there is already a replacement for denser fibers with a reddish birefringence. Day 14 fibers replaced in F3 and F4 for more mature collagen. At 21 days, all groups had intertwined type I collagen fibers. 
cellular activity of this group.

At day 21, all groups that used the F3 and F4 membranes as wound cover showed better retraction rates and histological aspects than the control group. These findings, therefore, suggest that the use of dressings for these wounds may be advantageous to the healing process.

\section{Conclusions}

This study described the development of a biocompatible double layer membrane based on biopolymers (chitosan and sodium alginate) for the delivery of polymyxin sulphate and lidocaine chloride, for wound healing. A scalable and organic solvent-free production procedure has been adopted to develop a non-toxic, of low-cost biomaterial. The obtained product was shown to be non-cytotoxic against fibroblasts. Its antimicrobial activity was confirmed in vitro using Gram-positive (Staphylococcus aureus) and Gram-negative (Pseudomonas aeruginosa) bacteria. The wound healing capacity of double layer membrane was confirmed in vivo, showing promising outcomes to be applied in human studies.

\section{CRediT authorship contribution statement}

D.M.L. Oliveira: Conceptualization, Investigation, Methodology. P. S. Rezende: Formal analysis, Investigation, Methodology. T.C. Barbosa: Formal analysis, Investigation, Methodology. L.N. Andrade: Resources, Software, Validation. C. Bani: Resources, Software, Validation. D.S. Tavares: Conceptualization, Investigation, Methodology. C.F. da Silva: Data curation, Investigation, Methodology, Validation. M.V. Chaud: Data curation, Investigation, Methodology, Validation. F. Padilha: Data curation, Investigation, Methodology, Validation, Writing - original draft. A. Cano: Resources, Software, Validation, Writing - review \& editing. R.L.C. de Albuquerque Júnior: Project administration, Investigation, Methodology, Supervision, Writing original draft, Funding acquisition. E.B. Souto: Conceptualization, Project administration, Validation, Writing - original draft, Writing review \& editing, Funding acquisition. P. Severino: Conceptualization, Project administration, Data curation, Validation, Supervision, Writing original draft, Writing - review \& editing, Funding acquisition.

\section{Declaration of Competing Interest}

The authors declare that they have no known competing financial interests or personal relationships that could have appeared to influence the work reported in this paper.

\section{Acknowledgements}

The authors acknowledge the Coordenação de Aperfeiçoamento de Pessoal de Nível Superior (CAPES/Brazil), Fundação de Amparo a Pesquisa do Estado de Sergipe (FAPITEC, MS/CNPq/FAPITEC/SE/SES N ${ }^{\circ}$ 06/2018) e do Conselho Nacional de Pesquisas (CNPq, Apoio a Projetos de Pesquisa/MCTI/CNPQ/Universal 14/2014) for supporting funds. EBS acknowledges the Portuguese Science and Technology Foundation (FCT) for the funded projects M-ERA-NET/0004/2015 (PAIRED) and UIDB/04469/2020 (strategic fund) financed from national funds, and co-financed Education (FCT/MEC) from national funds and FEDER, under the Partnership Agreement PT2020.

\section{References}

Ahmad, S., Minhas, M.U., Ahmad, M., Sohail, M., Abdullah, O., Badshah, S.F., 2018. Preparation and evaluation of skin wound healing chitosan-based hydrogel membranes. AAPS PharmSciTech 19, 3199-3209.

Alsarra, I.A., Betigeri, S.S., Zhang, H., Evans, B.A., Neau, S.H., 2002. Molecular weight and degree of deacetylation effects on lipase-loaded chitosan bead characteristics. Biomaterials 23, 3637-3644.
Andersen, B.M., 2019. Wound Care: Skin and Soft Tissue, Prevention and Control of Infections in Hospitals. Springer, pp. 273-277.

Barbosa, G.P., Debone, H.S., Severino, P., Souto, E.B., da Silva, C.F., 2016. Design and characterization of chitosan/zeolite composite films - Effect of zeolite type and zeolite dose on the film properties. Mater. Sci. Eng., C 60, 246-254.

Barreto, R.S., Quintans, J.S., Barreto, A.S., Albuquerque-Júnior, R.L., Galvão, J.G., Gonsalves, J.K., Nunes, R.S., Camargo, E.A., Lucca-Júnior, W., Soares, R., 2016. Improvement of wound tissue repair by chitosan films containing (-)-borneol, a bicyclic monoterpene alcohol, in rats. Int. Wound J. 13, 799-808.

Bassi da Silva, J., Ferreira, S.B.D.S., de Freitas, O., Bruschi, M.L., 2017. A critical review about methodologies for the analysis of mucoadhesive properties of drug delivery systems. Drug Dev. Ind. Pharm. 43, 1053-1070.

Behera, S.S., Das, U., Kumar, A., Bissoyi, A., Singh, A.K., 2017. Chitosan/TiO2 composite membrane improves proliferation and survival of L929 fibroblast cells: Application in wound dressing and skin regeneration. Int. J. Biol. Macromol. 98, 329-340.

Bigucci, F., Luppi, B., Cerchiara, T., Sorrenti, M., Bettinetti, G., Rodriguez, L., Zecchi, V., 2008. Chitosan/pectin polyelectrolyte complexes: selection of suitable preparative conditions for colon-specific delivery of vancomycin. Eur. J. Pharm. Sci. 35, 435-441.

Brandenburg, K.S., Rubinstein, I., Sadikot, R.T., Önyüksel, H., 2012. Polymyxin B selfassociated with phospholipid nanomicelles. Pharm. Dev. Technol. 17, 654-660.

Brothers, K.M., Stella, N.A., Hunt, K.M., Romanowski, E.G., Liu, X., Klarlund, J.K. Shanks, R.M., 2015. Putting on the brakes: Bacterial impediment of wound healing. Sci. Rep. 5, 14003.

Bueno, C.Z., Dias, A.M.A., de Sousa, H.J.C., Braga, M.E.M., Moraes, Â.M., 2014. Control of the properties of porous chitosan-alginate membranes through the addition of different proportions of Pluronic F68. Mater. Sci. Eng., C 44, 117-125.

Bui, V., Park, D., Lee, Y.-C., 2017. Chitosan combined with ZnO, TiO2 and Ag nanoparticles for antimicrobial wound healing applications: a mini review of the research trends. Polymers 9, 21.

Caramella, C.M., Rossi, S., Ferrari, F., Bonferoni, M.C., Sandri, G., 2015. Mucoadhesive and thermogelling systems for vaginal drug delivery. Adv. Drug Deliv. Rev. 92, 39-52.

Chantre, C.O., Hoerstrup, S.P., Parker, K.K., 2019. Engineering biomimetic and instructive materials for wound healing and regeneration. Curr. Opin. Biomed. Eng. 10, 97-106.

Corrêa, F.R.S., Schanuel, F.S., Moura-Nunes, N., Monte-Alto-Costa, A., Daleprane, J.B. 2017. Brazilian red propolis improves cutaneous wound healing suppressing inflammation-associated transcription factor NFkB. Biomed. Pharmacother. 86, $162-171$.

Debone, H.S., Lopes, P.S., Severino, P., Yoshida, C.M.P., Souto, E.B., da Silva, C.F., 2019. Chitosan/Copaiba oleoresin films for would dressing application. Int. J. Pharm. 555, $146-152$.

Desai, K.G.H., 2018. Polymeric drug delivery systems for intraoral site-specific chemoprevention of oral cancer. J. Biomed. Mater. Res. B Appl. Biomater. 106, 1383-1413.

Diniz, F.R., Maia, R.C.A.P., Rannier, L., Andrade, L.N., Chaud, M.V., da Silva, C.F., Corrêa, C.B., de Albuquerque Junior, R.L.C., da Costa, L.P., Souto, E.B., Severino, P., 2020. Silver nanoparticles-composing alginate/gelatin hydrogel improves wound healing in vivo. Nanomaterials 10, 390.

Fernandes, R.S., Moura, M.R.D., Aouada, F.A., 2017. Optimization of synthesis of intercalated nanocomposite hydrogels for future application in the medical area. Química Nova 40, 60-67.

Fonseca-Santos, B., Chorilli, M., 2017. An overview of polymeric dosage forms in buccal drug delivery: State of art, design of formulations and their in vivo performance evaluation. Mater. Sci. Eng., C 86, 129-143.

Frank, L.A., Sandri, G., D’Autilia, F., Contri, R.V., Bonferoni, M.C., Caramella, C., Frank, A.G., Pohlmann, A.R., Guterres, S.S., 2014. Chitosan gel containing polymeric nanocapsules: a new formulation for vaginal drug delivery. Int. J. Nanomed. 9, 3151.

Fransén, N., Björk, E., Edsman, K., 2008. Changes in the mucoadhesion of powder formulations after drug application investigated with a simplified method. J. Pharm. Sci. 97, 3855-3864.

Gallardo-Rivera, R., De Los Ángeles Aguilar-Santamaría, M., Silva-Bermúdez, P., GarcíaLópez, J., Tecante, A., Velasquillo, C., Román-Guerrero, A., Pérez-Alonso, C., Vázquez-Torres, H., Shirai, K., 2018. Polyelectrolyte complex of Aloe vera, chitosan, and alginate produced fibroblast and lymphocyte viabilities and migration. Carbohydr. Polym. 192, 84-94.

Garcia-Orue, I., Gainza, G., Gutierrez, F.B., Aguirre, J.J., Evora, C., Pedraz, J.L., Hernandez, R.M., Delgado, A., Igartua, M., 2017. Novel nanofibrous dressings containing rhEGF and Aloe vera for wound healing applications. Int. J. Pharm. 523, 556-566.

Guadarrama-Acevedo, M.C., Mendoza-Flores, R.A., Del Prado-Audelo, M.L., UrbánMorlán, Z., Giraldo-Gomez, D.M., Magaña, J.J., González-Torres, M., ReyesHernández, O.D., Figueroa-González, G., Caballero-Florán, I.H., FloránHernández, C.D., Florán, B., Cortés, H., Leyva-Gómez, G., 2019. Development and evaluation of alginate membranes with curcumin-loaded nanoparticles for potential wound-healing applications. Pharmaceutics 11.

Gupta, B., Ramasamy, T., Poudel, B.K., Pathak, S., Regmi, S., Choi, J.Y., Son, Y., Thapa, R.K., Jeong, J.-H., Kim, J.R., Choi, H.-G., Yong, C.S., Kim, J.O, 2017. Development of bioactive PEGylated nanostructured platforms for sequential delivery of doxorubicin and imatinib to overcome drug resistance in metastatic tumors. ACS Appl. Mater. Interfaces 9, 9280-9290.

Han, G., Ceilley, R., 2017. Chronic wound healing: a review of current management and treatments. Adv. Therapy 34, 599-610.

Harm, S., Gabor, F., Hartmann, J., 2016. Low-dose polymyxin: an option for therapy of Gram-negative sepsis. Innate Immun. 22, 274-283. 
Hissae Yassue-Cordeiro, P., Zandonai, C.H., Pereira Genesi, B., Santos Lopes, P., SanchezLopez, E., Garcia, M.L., Camargo, N.R., Fernandes-Machado, P., Severino, E.B.S., Ferreira Da Silva, C., 2019. Development of chitosan/silver sulfadiazine/zeolite composite films for wound dressing. Pharmaceutics 11.

Insua, I., Zizmare, L., Peacock, A.F., Krachler, A.M., Fernandez-Trillo, F., 2017. Polymyxin B containing polyion complex (PIC) nanoparticles: Improving the antimicrobial activity by tailoring the degree of polymerisation of the inert component. Sci. Rep. 7, 9396.

ISO, 2009. International Standards Organization ISO 10993-5: 2009. Biological evaluation of medical devices-Part 5: Tests for in vitro cytotoxicity.

Karimkhani, C., Dellavalle, R.P., Coffeng, L.E., Flohr, C., Hay, R.J., Langan, S.M., Nsoesie, E.O., Ferrari, A.J., Erskine, H.E., Silverberg, J.I., Vos, T., Naghavi, M., 2017. Global skin disease morbidity and mortality: An update from the global burden of disease study 2013. JAMA Dermatol. 153, 406-412.

Kesici, S., Kesici, U., Ulusoy, H., Erturkuner, P., Turkmen, A., Arda, O., 2018. Effects of local anesthetics on wound healing. Brazil. J. Anesthesiol. 68, 375-382.

Khutoryanskiy, V.V., 2011. Advances in mucoadhesion and mucoadhesive polymers. Macromol. Biosci. 11, 748-764.

Kulkarni, R.V., Sreedhar, V., Mutalik, S., Setty, C.M., Sa, B., 2010. Interpenetrating network hydrogel membranes of sodium alginate and poly (vinyl alcohol) for controlled release of prazosin hydrochloride through skin. Int. J. Biol. Macromol. 47, 520-527.

Lino, M.E., Ruela, A.L., Trevisan, M.G., Pereira, G.R., 2017. Influence of hydration and crosslinking in transdermal delivery of nicotine from chitosan-based gels by thermal analysis. J. Therm. Anal. Calorim. 130, 1455-1461.

Liu, X., Nielsen, L.H., Kłodzińska, S.N., Nielsen, H.M., Qu, H., Christensen, L.P., Rantanen, J., Yang, M., 2018. Ciprofloxacin-loaded sodium alginate/poly (lactic-coglycolic acid) electrospun fibrous mats for wound healing. Eur. J. Pharmaceut. Biopharmaceut. 123, 42-49.

Mahmoud, A.A., Salama, A.H., 2016. Norfloxacin-loaded collagen/chitosan scaffolds for skin reconstruction: Preparation, evaluation and in-vivo wound healing assessment. Eur. J. Pharm. Sci. 83, 155-165.

Mendes, M.M.P.G., de Jesus Souza, C.S.A., 2017. Aplicação de modelos animais na pesquisa biomédica experimental. Revista de Saúde da Faciplac 4.

Milcheski, D.A., Mendes, R.R.D.S., Freitas, F.R.D., Zaninetti, G., Júnior, M., Ayres, A., Gemperli, R., 2017. Brief hospitalization protocol for pressure ulcer surgical treatment: outpatient care and one-stage reconstruction. Revista do Colégio Brasileiro de Cirurgiões 44, 574-581.

Morales, J.O., Fathe, K.R., Brunaugh, A., Ferrati, S., Li, S., Montenegro-Nicolini, M., Mousavikhamene, Z., McConville, J.T., Prausnitz, M.R., Smyth, H.D., 2017. Challenges and future prospects for the delivery of biologics: oral mucosal, pulmonary, and transdermal routes. AAPS J. 19, 652-668.

Morgado, P.I., Miguel, S.P., Correia, I.J., Aguiar-Ricardo, A., 2017. Ibuprofen loaded PVA/chitosan membranes: A highly efficient strategy towards an improved skin wound healing. Carbohydr. Polym. 159, 136-145.

Muzzarelli, R.A., 2009. Genipin-crosslinked chitosan hydrogels as biomedical and pharmaceutical aids. Carbohydr. Polym. 77, 1-9.

Naseri-Nosar, M., Ziora, Z.M., 2018. Wound dressings from naturally-occurring polymers: A review on homopolysaccharide-based composites. Carbohydr. Polym. 189, 379-398.

Olczyk, P., Mencner, Ł., Komosinska-Vassev, K., 2014. 2014The role of the extracellular matrix components in cutaneous wound healing. BioMed Res. Int. 2014.

Othman, Z., Pastor, B.C., van Rijt, S., Habibovic, P., 2018. Understanding interactions between biomaterials and biological systems using proteomics. Biomaterials 167, 191-204.

Pathak, P., Nagarsenker, M., 2009. Formulation and evaluation of lidocaine lipid nanosystems for dermal delivery. Aaps Pharmscitech 10, 985.

Ramasamy, T., Munusamy, S., Ruttala, H.B., Kim, J.O., 2020. Smart nanocarriers for the delivery of nucleic acid-based therapeutics: A comprehensive review. Biotechnol. J. 1900408.

Ramasamy, T., Ruttala, H.B., Gupta, B., Poudel, B.K., Choi, H.G., Yong, C.S., Kim, J.O., 2017. Smart chemistry-based nanosized drug delivery systems for systemic applications: A comprehensive review. J. Controll. Release: Off. J. Controll. Release Soc. 258, 226-253.

Rodrigues, H.G., Vinolo, M.A., Sato, F.T., Magdalon, J., Kuhl, C.M., Yamagata, A.S., Pessoa, A.F., Malheiros, G., Dos Santos, M.F., Lima, C., Farsky, S.H., Camara, N.O., Williner, M.R., Bernal, C.A., Calder, P.C., Curi, R., 2016. Oral administration of linoleic acid induces new vessel formation and improves skin wound healing in diabetic rats. PLoS ONE 11, e0165115.

Seth, D., Cheldize, K., Brown, D., Freeman, E.F., 2017. Global Burden of Skin Disease: Inequities and Innovations. Curr. Dermatol. Rep. 6, 204-210.

Severino, P., Chaud, M.V., Shimojo, A., Antonini, D., Lancelloti, M., Santana, M.H.A., Souto, E.B., 2015. Sodium alginate-cross-linked polymyxin B sulphate-loaded solid lipid nanoparticles: antibiotic resistance tests and HaCat and NIH/3T3 cell viability studies. Colloids Surf., B 129, 191-197.

Severino, P., Feitosa, A., Lima-Verde, I.I.B., Chaud, M., Da Silva, C., De Lima, R., Amaral, R., Andrade, L., 2018. Production and characterization of mucoadhesive membranes for anesthetic vehiculation. Chem. Eng. Trans. 64, 421-426.

Severino, P., Silveira, E.F., Loureiro, K., Chaud, M.V., Antonini, D., Lancellotti, M., Sarmento, V.H., da Silva, C.F., Santana, M.H.A., Souto, E.B., 2017. Antimicrobial activity of polymyxin-loaded solid lipid nanoparticles (PLX-SLN): Characterization of physicochemical properties and in vitro efficacy. Eur. J. Pharm. Sci. 106, 177-184.

Shtenberg, Y., Goldfeder, M., Prinz, H., Shainsky, J., Ghantous, Y., El-Naaj, I.A., Schroeder, A., Bianco-Peled, H., 2018. Mucoadhesive alginate pastes with embedded liposomes for local oral drug delivery. Int. J. Biol. Macromol. 111, 62-69.

Smith, M.A., Cho, K., Rodgers, P., 2018. Provider perspectives on topical analgesics. J. Pain Palliat. Care Pharmacother. 32, 44-48.

Song, J.J., Salcido, R., 2011. Use of honey in wound care: an update. Adv. Skin Wound Care 24, 40-44.

Souto, E.B., Severino, P., Yassue-Cordeiro, P.H., Felisbino, R.F., Gomes, E.L., da Silva, C. F., 2017. Organic/Zeolites Nanocomposite Membranes Organic-Inorganic Composite Polymer Electrolyte Membranes. Springer, pp. 73-98.

Sultana, J., Molla, M.R., Kamal, M., Shahidullah, M., Begum, F., Bashar, M.A., 2009. Histological differences in wound healing in maxillofacial region in patients with or without risk factors. Bangl. J. Pathol. 24, 3-8.

Szekalska, M., Sosnowska, K., Zakrzeska, A., Kasacka, I., Lewandowska, A., Winnicka, K., 2017. The influence of chitosan cross-linking on the properties of alginate microparticles with metformin hydrochloride-in vitro and in vivo evaluation. Molecules 22, 182.

Teo, S., Lee, S., Rathbone, M., Gan, S., 2017. Polymeric materials as platforms for topical drug delivery: a review. Int. Pharm. Pharm. Sci. 9, 14-20.

Thacharodi, D., Rao, K.P., 1996. Rate-controlling biopolymer membranes as transdermal delivery systems for nifedipine: development and in vitro evaluations. Biomaterials 17, 1307-1311.

Turk, H.F., Monk, J.M., Fan, Y.Y., Callaway, E.S., Weeks, B., Chapkin, R.S., 2013. Inhibitory effects of omega-3 fatty acids on injury-induced epidermal growth factor receptor transactivation contribute to delayed wound healing. Am. J. Physiol. Cell Physiol. 304, C905-C917.

Waite, A., Gilliver, S., Masterson, G., Hardman, M., Ashcroft, G., 2010. Clinically relevant doses of lidocaine and bupivacaine do not impair cutaneous wound healing in mice. Br. J. Anaesth. 104, 768-773.

Wang, J., Chen, C., 2014. Chitosan-based biosorbents: modification and application for biosorption of heavy metals and radionuclides. Bioresour. Technol. 160, 129-141.

Wang, Z., Zheng, L., Li, C., Wu, S., Xiao, Y., 2017. Preparation and antimicrobial activity of sulfopropyl chitosan in an ionic liquid aqueous solution. J. Appl. Polym. Sci. 134.

Wu, T., Huang, J., Jiang, Y., Hu, Y., Ye, X., Liu, D., Chen, J., 2018. Formation of hydrogels based on chitosan/alginate for the delivery of lysozyme and their antibacterial activity. Food Chem. 240, 361-369.

Yassue-Cordeiro, P.H., Severino, P., Souto, E.B., Gomes, E.L., Yoshida, C.M., de Moraes, M.A., da Silva, C.F., 2018. Chitosan-based nanocomposites for drug delivery. In: Applications of Nanocomposite Materials in Drug Delivery. Elsevier, pp. 1-26.

Zeugolis, D.I., Coentro, J.Q., Raghunath, M., Pugliese, E., 2018. Wound healing and scar wars. Adv. Drug Deliv. Rev. 129, 1-3. 